

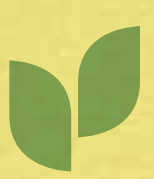

\section{MESSAGE FROM THE DIRECTOR}

The mission of the Technology Innovation and Development program within the DOE Office of Environmental Management is to transform science and innovation into practical solutions for environmental clean-up.

During fiscal year 2011 (October 2010-September 2011), EM focused upon accelerating environmental clean-up by expeditiously filling identified gaps in available knowledge and technology in the EM program areas.

This report describes some of the approaches and transformational technologies in tank waste processing, groundwater and soil remediation, nuclear materials disposition, and facility deactivation and decommissioning developed during fiscal year 2011 that will enable EM to meet its most pressing program goals.

This report also describes fiscal year 2011 activities of the Office of Technology Innovation and Development's cross-cutting International Program, which facilitates engagement with institutions in other countries to accelerate accomplishment of every EM program area mission. EM is presently reaping benefits from, for example, an international research program on the durability of the glass waste form for high-level tank waste; collaboration with researchers in Chernobyl, Ukraine, on radiation ecology; information exchange with organizations in the United Kingdom, Canada and France on plutonium and spent nuclear fuel management; and adaptation of a technology invented in the UK for use in decommissioning contaminated DOE facilities.

Through leadership in integration, collaboration and communication, we will accelerate environmental clean-up and reduce costs.

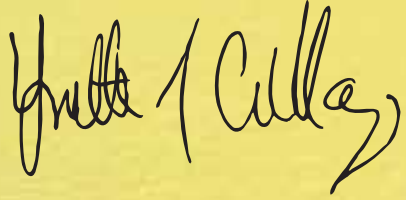

Office of Technology Innovation \& Development Office of Environmental Management U.S. Department of Energy

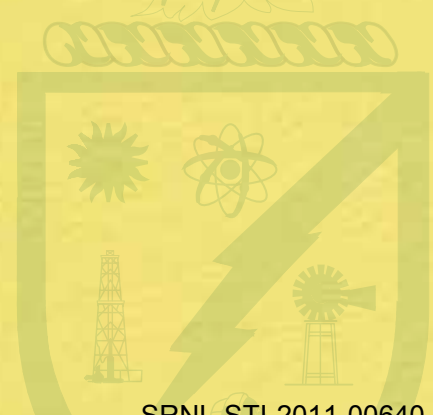

SRNL-STI-2011-00640
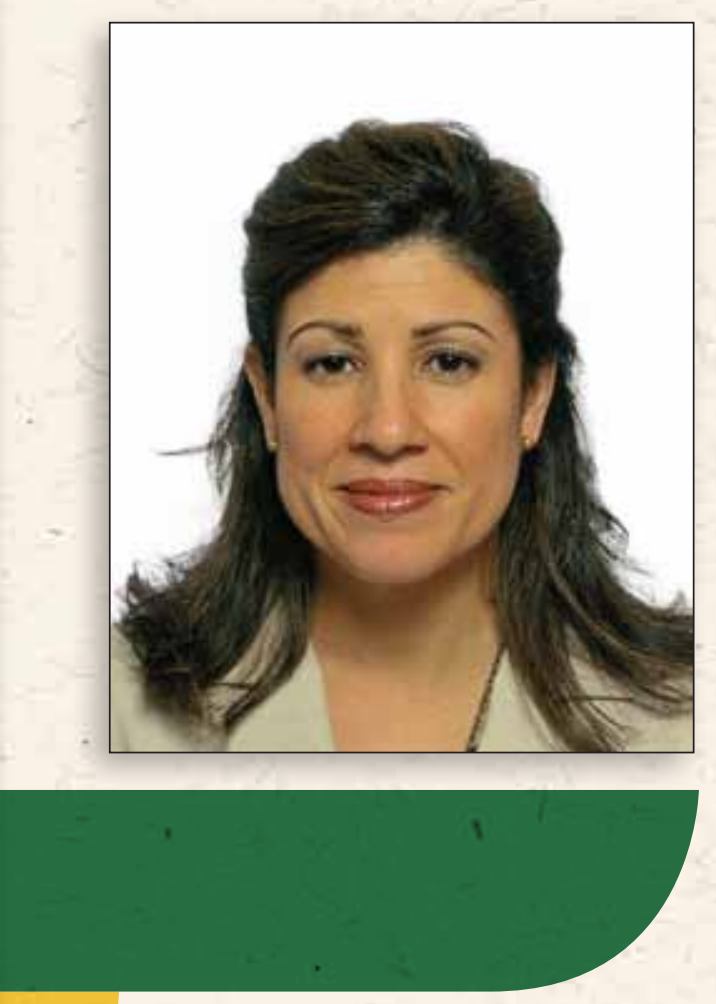


\section{TABLE OF CONTENTS}

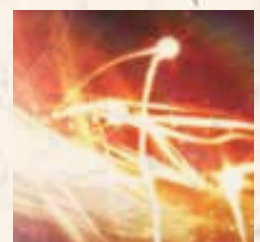

TANK WASTE PROCESSING

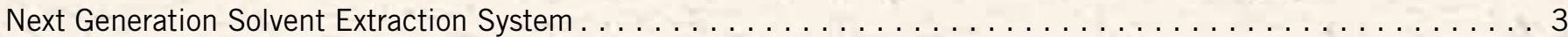

Fluidized Bed Steam Reforming Sodium-Alumino-Silicate Low-Activity Waste Form $\ldots \ldots \ldots \ldots \ldots \ldots \ldots \ldots$

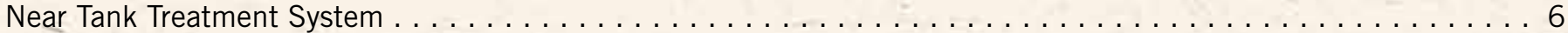

Joint EM-NE-International Evaluation of Long-Term Behavior of Glass High-Level Waste Form $\ldots \ldots \ldots \ldots \ldots 7$

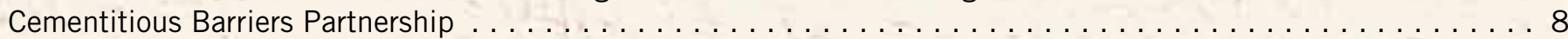

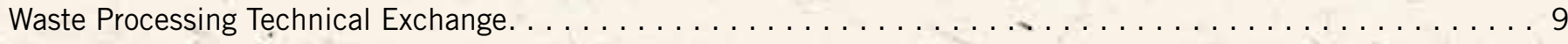

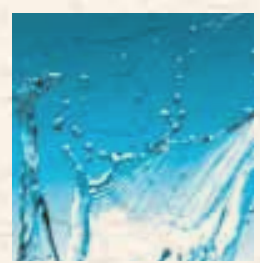

\section{GROUNDWATER \& SOIL REIMEDIATION}

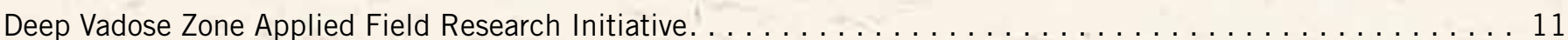

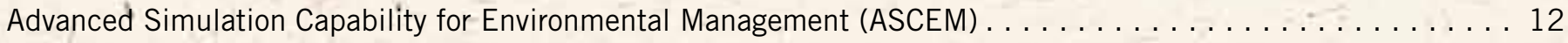

Attenuation-Based Remedies for the Subsurface Applied Field Research Initiative $\ldots \ldots \ldots \ldots \ldots \ldots \ldots \ldots 13$

Applied Field Research Initiative for the Remediation of Mercury \& Industrial Contaminants . . . . . . . . . 14

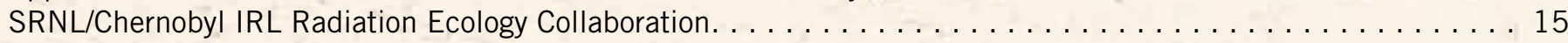

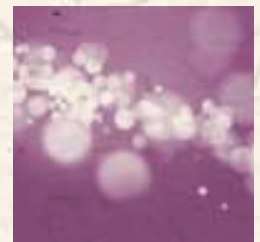

\section{NUCLEAR MATERIALS DISPOSITION}

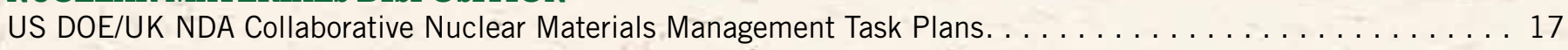

US DOE/UK NDA Workshop on Plutonium Management $\ldots \ldots \ldots \ldots \ldots \ldots \ldots \ldots \ldots \ldots \ldots \ldots \ldots \ldots \ldots 18$

DOE SRNL/UK Univ. of Manchester Partnership to Evaluate Stress Corrosion Cracking of Plutonium Storage Containers . . . . 19

US DOE/ Atomic Energy of Canada Ltd. Spent Nuclear Fuel Collaboration . . . . . . . . . . . . . . . . . . . . . . . . 20

US DOE/ PURAM of Hungary Information Exchange on Spent Nuclear Fuel Dry Storage. $\ldots \ldots \ldots \ldots \ldots \ldots \ldots \ldots \ldots 21$

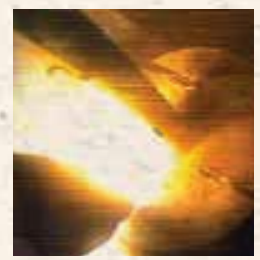

DEACTIVATION AND DECOIMIMISSIONING

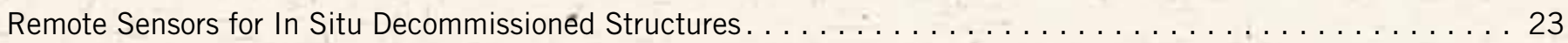

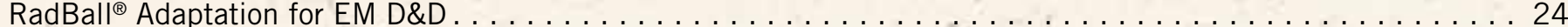

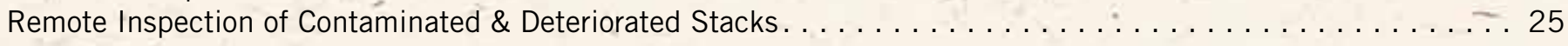

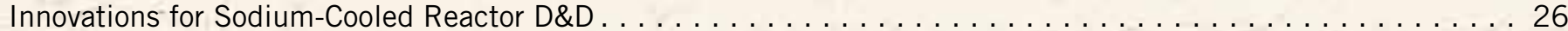

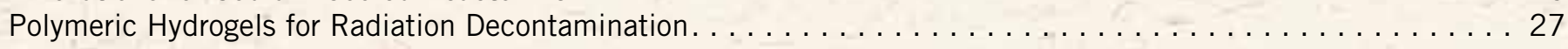

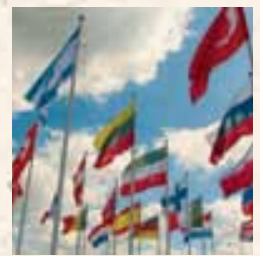

\section{INTERNATIONAL PROGRAIM}

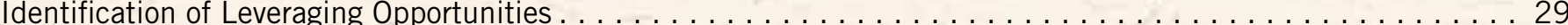

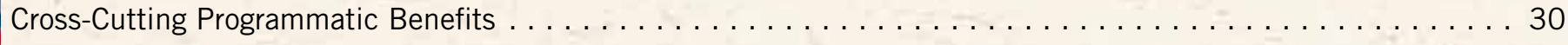




\section{TANK WASTE PROCESSING}

The Department of Energy's Office of Environmental Management (DOE EM) is responsible to safely retrieve, stabilize and dispose of about 88 million gallons of radioactive waste stored in 230 underground tanks at DOE's Hanford, Savannah River, and Idaho sites and close the waste tanks. The chemistry and forms of the wastes vary widely, as do the tanks containing them. Conducting applied research and development to resolve unique and complex challenges is an integral part of the tank waste program.

The Office of Waste Processing within the Office of Technology Innovation and Development provides transformational technologies to reduce the life-cycle cost and schedule of tank waste processing by

1. increasing processing rates and/or efficiencies

2. removing material from the process flow

3. accelerating tank waste retrieval and closure, and

4. developing and reducing identified project and safety risks:

During fiscal year 2011, waste processing technologies were matured for expeditious deployment to accelerate the tank waste mission. Some major activities contributing to that effort are these:

- Next Generation Solvent Extraction System

- Fluidized Bed Steam Reforming Sodium-Alumino-Silicate Low-Activity Waste Form

- Near Tank Treatment System

- Joint EM-NE-International Evaluation of Long-Term Behavior of Glass High-Level Waste Form

- Cementitious Barriers Partnership

- Waste Processing Technical Exchange. 


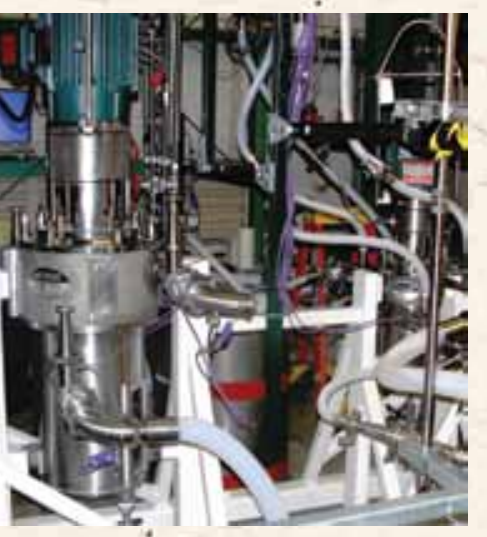

Full-scale contactors with associated pumps, tanks, piping, and an integrated coalescer in the SRNL EDL

\section{Next Generation Solvent Extraction System}

As part of the Enhanced Tank Waste Strategy, improving the performance of the Modular Caustic Side Solvent Extraction (CSSX) Unit (MCU) at the Savannah River Site (SRS) was given high priority.

The MCU was designed as a pilot-scale facility to treat a small inventory of low-curie waste at limited through-put until the Salt Waste Processing Facility (SWPF) under construction at SRS came on line. From its radioactive start-up in April 2008 until the end of August 2011, the MCU has removed cesium from approximately 2 million gallons of alkaline solution. The cesium removal is performed using an extractant called BOBCalixC6 formulated by Oak Ridge National Laboratory (ORNL). The MCU uses centrifúgal contactors to provide mechanical mixing and phase separation of the solvent and the alkaline waste. ORNL has identified an improved solvent system using a more soluble extractant called MaxCalix, which is projected to raise the decontamination factor in MCU substantially (from about 200 to more than 40,000) and to allow the continued use of MCU for processing higher-activity waste solutions as well as to enhance the performance of the SWPF.

During fiscal year 2011, ORNL and Savannah River National Laboratory (SRNL) performed a variety of tasks to develop the Next Generation CSSX Solvent (NGCS) extraction system with the objective of deploying the new system in MCU in late calendar year 2011.

Researchers optimized the chemical properties of the solvent by performing radiation stability tests, measuring the effects of temperature on solvent stability and effectiveness, studying the effects of solvent degradation impurities on solvent performance, and evaluating alternate components to improve solvent characteristics. Researchers also performed a series of Extraction, Scrub, Strip tests using both simulated and actual tank waste to evaluate the performance of the new solvent and compare it to the existing solvent.

In addition, researchers completed tests of a $2-\mathrm{cm}$ centrifugal contactor apparatus with 12 contactor stages. The first test used non-radioactive simulated waste to test the hydraulic operation of process equipment and verify the performance of the solvent system, and the second used actual radioactive tank waste. The testing indicates that waste decontamination with the improved solvent far exceeds the performance of the baseline solvent and meets processing targets for the new solvent.

The next development steps include using single full-scale contactors to confirm correct hydraulic operation and mass transfer at full-scale flow conditions. In collaboration with the liquid waste contractor at SRS, Savannah River Remediation, SRNL installed single V5 and V10 centrifugal contactors with associated pumps, tanks, piping, and an integrated coalescer in the SRNL Engineering Development Laboratory (EDL) to simulate full-scale feed rates to the contactors and evaluate new coalescer designs. Additional tests will also evaluate high- and low-flow conditions through the contactors. Preliminary data from the contactor tests show good hydraulic operations; chemical analyses are in progress to determine mass transfer efficiency in the individual contactors. Testing also includes contacting the solvent with media samples over an extended period to confirm that the new solvent is compatible with materials of construction used in MCU and SWPF. Results from the first two contact periods are complete and show behavior very comparable to the current solvent.

SRNL-STI-2011-00640 


\section{Fluidized Bed Steam Reforming Sodium-Alumino-Silicate Low-Activity Waste Form}

Supplemental treatment of low-activity waste (LAW) in addition to LAW vitrification in the Waste Treatment and Immobilization Plant (WTP) under construction at the Hanford site is necessary to complete the tank waste clean-up mission in the time required by the Hanford Federal Facility Agreement and Consent Order. In addition, completing tank waste processing at the earliest practical date will realize significant cost avoidance since the life-cycle cost is strongly influenced by the operating duration of the WTP. The chosen supplemental treatment technology will immobilize retrieved LAW into a solidified waste form. The solidified waste, as with vitrified LAW, will be disposed of on the Hanford site in the Integrated Disposal Facility.

Fluidized Bed Steam Reforming (FBSR) to produce a sodium-alumino-silicate (NAS) waste form is a promising technology for supplemental treatment of LAW at the Hanford site.

The FBSR technology invented by Thermal Organic Reduction (ThOR) Treatment Technologies (TTT) converts radioactive liquid wastes to solid mineral particles suitable for LAW near-surface burial. Sodalite, the granular mineralized NAS waste form produced by co-processing the waste with kaolin clay, has been shown to be as durable as LAW glass. Sodalite contains cage-like structures that retain radionuclides so that they do not readily leach out of the FBSR waste form.

A Bench-scale Steam Reformer (BSR) was designed and constructed at the Savannah River National Laboratory in 2010 to treat actual radioactive wastes to confirm the findings of the nonradioactive FBSR pilot-scale tests performed in 2001 and 2004 and the engineering-scale tests performed in 2008. Demonstrating the similarity of the radioactive mineral products and their durability to the non-radioactive mineral products reveals the suitability of the waste form for disposal at Hanford based on the 2003 Risk Assessment of Supplemental Treatment Waste Forms.

During fiscal year 2011, three studies using actual LAW of different constituents were performed in the BSR. For each radioactive test, initial testing was performed on a simulant of the particular tank waste to determine the operational parameters for the BSR. The first LAW study used LAW from Savannah River Site Tank 50 chemically trimmed to resemble Hanford's blended 68-tank average LAW. The next study was performed on actual waste from Hanford Tank SX-105 containing moderate concentrations of anions such as chlorine and sulfate. Hanford \#2 testing was performed on actual waste from Hanford Tank AN-103, which is low-anion, high-sodium waste. Hanford \#3 testing, of a high-chromium and high-anion mixture of Hanford Tank AZ-101 and Tank AZ- 102 wastes, is currently scheduled to commence later in calendar year 2011.

Over the past nine months, X-Ray Absorption Spectroscopy studies have been performed at the Stanford Synchrotron Radiation Lightsource located at Stanford Linear Accelerator Center National Accelerator, confirming that the sodalite minerals from the non-radioactive and radioactive BSR campaigns do indeed sequester appropriate radionuclides and their surrogates. 
The mineral products from the non-radioactive and radioactive first LAW and first Hanford LAW studies have been tested by the Environmental Protection Agency's Toxicity Characteristic Leaching Procedure and by the American Society for Testing and Materials standard for determining the chemical durability of nuclear and other crystalline forms. The results compare favorably to the results obtained on the mineral product from the 2001 and 2004 pilot-scale testing and the 2008 engineering-scale testing.

- Single Pass Flow Through tests have been initiated at Pacific Northwest National Laboratory on the non-radioactive and radioactive tests for comparison with the previous pilot-scale testing. In addition, Pressure Unsaturated Flow tests have been initiated on the non-radioactive test from the first LAW study for comparison with the previous pilot-scale testing.

FY2011 chemical processing as well as regulatory and performance testing have been encouraging and indicate that FBSR to produce the NAS waste form is a viable option for treatment of Hanford LAW and disposal in the Hanford IDF.

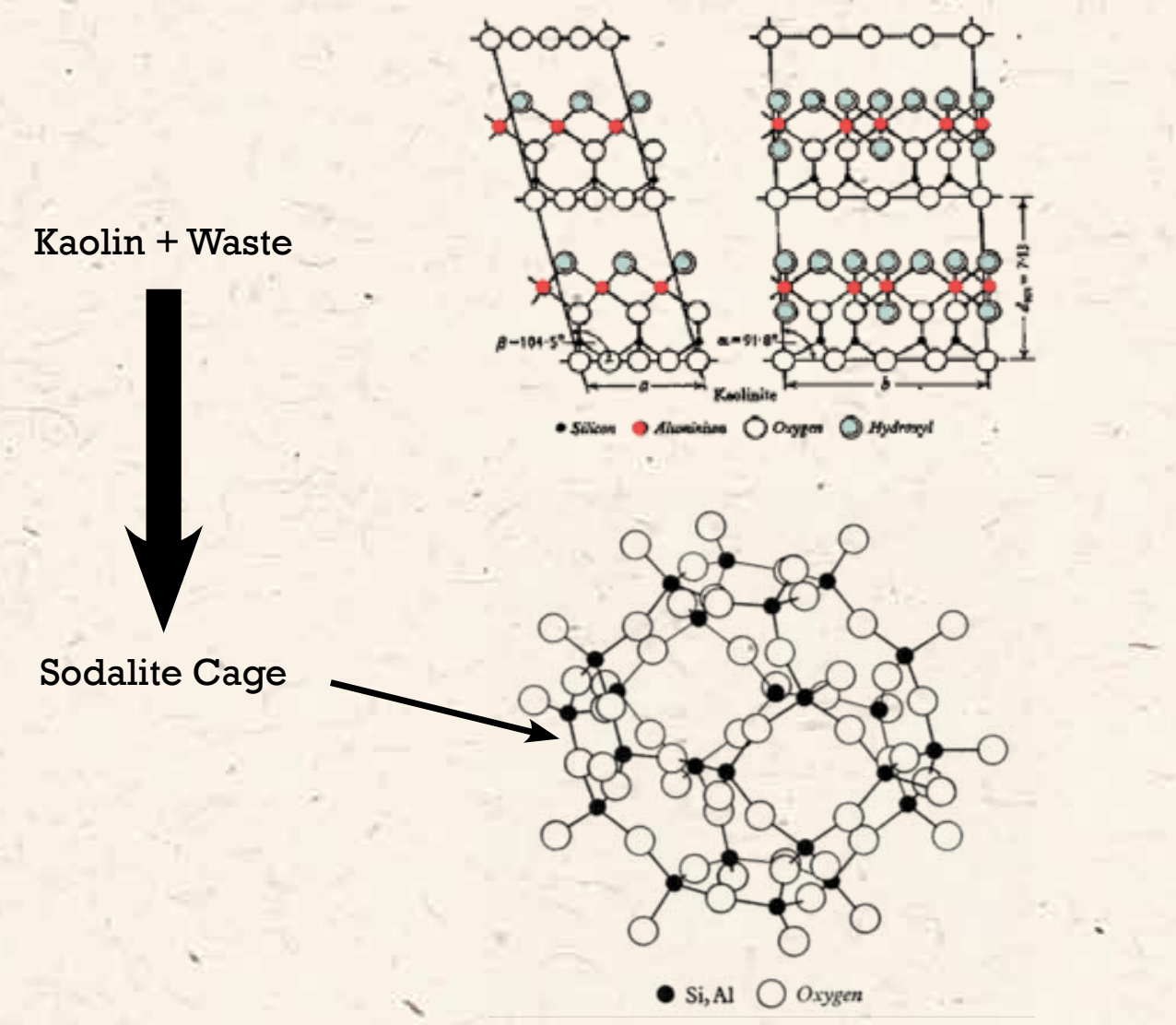




\section{Near Tank Treatment System}

The modular Near Tank Treatment System (NTTS) will separate aluminum and cesium from Hanford tank wastes while minimizing added sodium. Separating low-activity waste (LAW) from high-level waste (HLW) before the Waste Treatment and Immobilization Plant (WTP) becomes operational as well as reducing the volume of waste to be processed will decrease the duration and cost of WTP operations. The stages of the NTTS process are these:

1. HLW from Hanford's SX or S Tank Farm consisting of radioactive sludge and supernate containing cesium and nonradioactive aluminum is first treated by continuous sludge leaching to dissolve the aluminum; the remaining leached solids are returned to a sludge tank for HLW vitrification when the WTP starts up.

2. The liquid waste stream containing aluminum and cesium is filtered to remove residual sludge and is then treated by ion exchange to remove the radioactive cesium; the cesium is eluted and returned to the tanks for later HLW vitrification.

3. The resulting high-aluminum LAW stream is treated by sodium extraction to retrieve sodium hydroxide--added in the first stage to dissolve the aluminum--for recycle back to the beginning of the NTTS process.

The NTTS comprises three modules that may be deployed at or near the waste tanks: Continuous Sludge Leaching (CSL), Near Tank Cesium Removal (NTCR), and Electrochemical Caustic Recovery. Previously tested separately at bench scale, the NTTS technologies were successfully demonstrated at pilot scale in 2011.

As part of the DOE EM's Advanced Remediation Technologies (ART) Program, Parsons Infrastructure and Technology Group, Inc. and Battelle-Pacific Northwest developed CSL and NTCR for NTTS. In 2011, Parsons and Battelle demonstrated at pilot-scale the operability of those two major subsystems of the NTTS as well as longtime steady-state operation of the integrated processes. Results of the CSL demonstration indicate $60-90 \%$ removal of boehmite, the principal aluminum oxide in the waste stream, which is 2 to 4 times higher boehmite removal than can be achieved in the WTP batch process. The NTCR effectively removed the cesium.

The addition of sodium hydroxide during CSL increases the sodium inventory of LAW. Ceramatec Inc., Salt Lake City, Utah, has developed a process in which an electric field across a sodium ( $\mathrm{Na}$ ) super ionic conductor (NaSICON) ceramic membrane removes sodium from LAW and supplemental waste streams. In

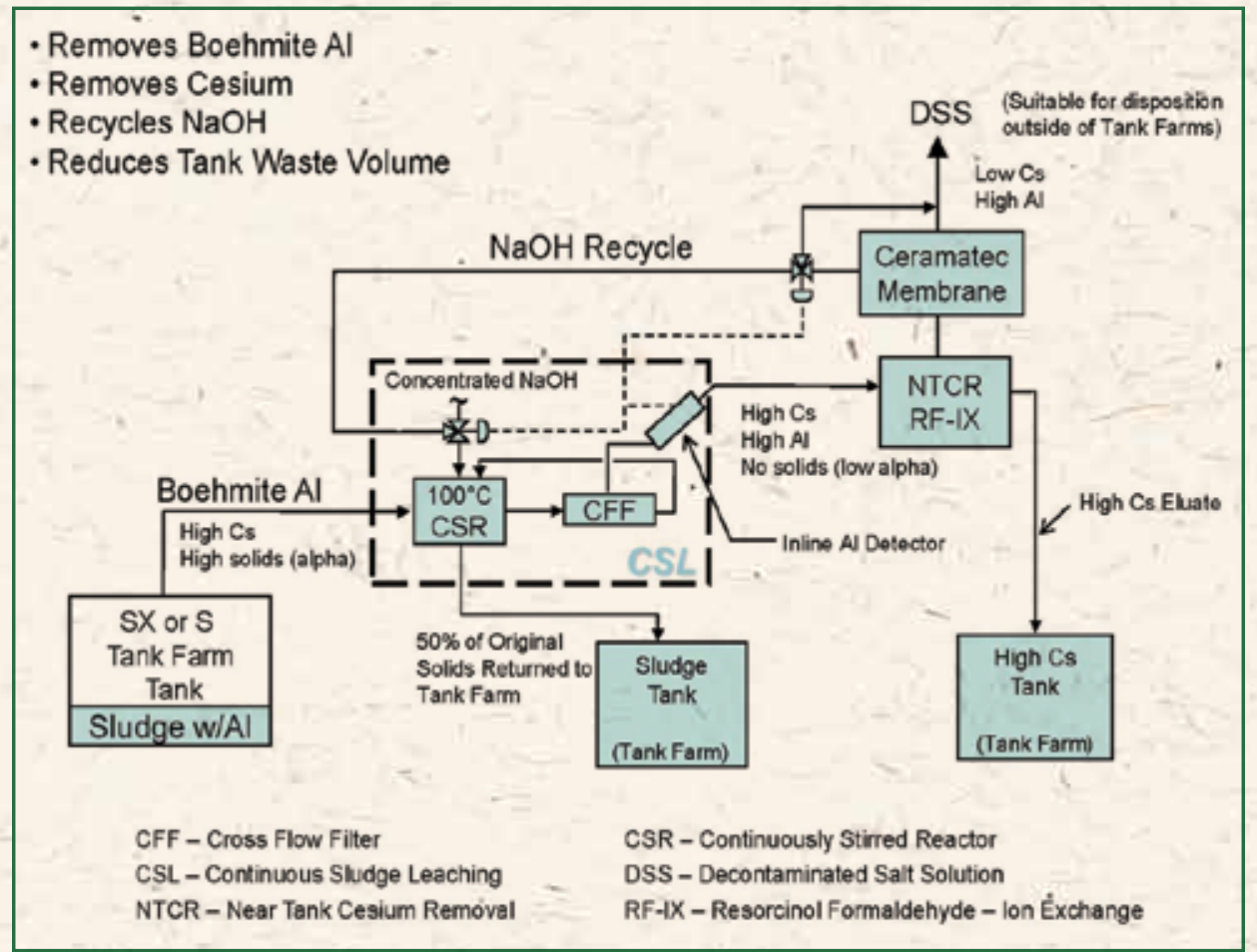


2011, operation of a stand-alone Caustic Recycling Unit (CRU) employing the Ceramatec membrane successfully demonstrated safe removal of up to 68 mole \% of sodium from NTCR effluent, reducing the LAW volume by as much as $39 \%$. The $\mathrm{CRU}$ regenerated the sodium to "clean" sodium hydroxide to be recycled to CSL.

Next steps are to complete detailed design and construction of the full-scale, fully integrated system to be deployed at the Hanford waste tanks to process actual waste.

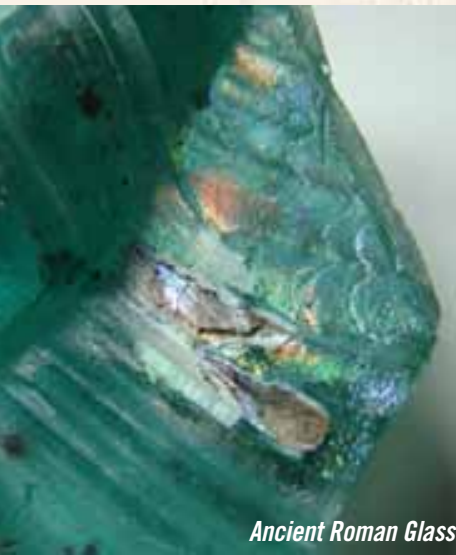

\section{Joint EM-NE-International Evaluation of Long-Term Behavior of Glass High-Level Waste Form}

Glass is used worldwide to immobilize, or vitrify, high level waste (HLW) from the reprocessing of spent nuclear fuel and targets. Radioactive constituents are chemically incorporated into molten glass, which is then decanted to large stainless steel canisters and cooled to a solid state. The world has been safely vitrifying HLW and storing the vitrified waste for several decades; the United States has been doing so since 1996. The vitrified waste is intended for permanent geologic disposal.

To confirm that the glass waste form would continue to render the HLW innocuous for thousands of years, DOE initiated an international research program in 2009. Charter participation came from the United States (jointly sponsored by the DOE Offices of Environmental Management and Nuclear Energy), France (CEA, Nantes, AREVA), Belgium (SCK-CEN), the United Kingdom (NNL, Sheffield), and Japan (Kyushu and JAEA); additional members have since joined. This international collaboration is developing data and expanding understanding of the behavior of the HLW glass waste form over geologic time scales in a variety of disposal environments

In 2011, the international collaboration achieved three significant accomplishments:

1. A detailed integrated plan for understanding the long-term behavior of glass and developing an international consensus rate law was completed and peer reviewed.

2. Ancient glass samples exposed to sea water for roughly 2000 years were received by United States researchers at Pacific Northwest National Laboratory and characterized using state of the art atom probe tomography methods to determine the role of alteration products on the long-term corrosion of glass.

3. Two-year-old static glass tests conducted to determine corrosion under near saturation conditions were terminated and characterized.

In its 2011 Waste Forms Technology and Performance: Final Report requested by DOE, the US National Research Council notes some of the benefits of continuing waste form investigation: "Incorporating new science and technology could lead to increased program efficiencies, reduced lifecycle costs and risks, and advanced scientific understanding of, and stakeholder confidence in, waste form behavior in different disposal environments." 


\section{Cementitious Barriers Partnership}

Sponsored by the DOE EM Office of Waste Processing, the Cementitious Barriers Partnership (CBP) works to improve understanding and prediction of the structural, hydraulic, and chemical performance over time frames extending from hundreds to thousands of years of cementitious materials and waste forms used primarily in nuclear waste disposal. These cementitious barriers are exposed to dynamic environmental conditions that cause changes in material properties via aging, chloride attack, sulfate attack, carbonation, oxidation, and primary constituent leaching.

The objective of the CBP is to develop a set of computational tools to reduce the uncertainties of current methodologies for performance assessment (PA), ultimately reducing both the extent of potential future releases and the migration rate of contaminants. Partners in the collaborative program are DOE, the US Nuclear Regulatory Commission, the US National Institute of Standards and Technology (NIST), the Savannah River National Laboratory, Vanderbilt University (VU), the Consortium for Risk Evaluation with Stakeholder Participation/VU, the Energy Research Center of the Netherlands, and SIMCO, Inc.

Recent activities to advance the CBP objective have included:

- Demonstrating the capabilities of partner software on a prototype case for CBP

- Sponsoring a test bed workshop to provide future data to validate cementitious material performance modeling

- Providing PA support work on cementitious material degradation specifically in support of the SRS Saltstone Disposal Facility

- Developing a dynamic-link library (DLL) interface that will now allow external CBP codes to be integrated with GoldSim allowing results to be examined probabilistically

- Developing initial integration of CBP state-of-the-art models that provide predictions of barrier performance over welldefined regimes

- Developing a numerical methodology to simulate the degradation of concrete vaults exposed to aggressive sulfate-containing pore solution of the low activity nuclear wastes -

- Implementing experimental programs that include: 1) testing to verify or improve conceptual models of process coupling, 2) measurements of needed parameters for the new models, and 3) integration of new leaching assessment methodologies under development by the US Environmental Protection Agency and applicable to a range of waste form types.

Greater integration and application of CBP tools is planned for fiscal year 2012. An initial version of the CBP Integrated Toolbox containing individual, modules already developed will be released. Also, an initial version of a new tool that will eventually be added to the Integrated Toolbox will be released; developed by NIST, THAMES is designed to predict changes in physical and transport properties of cementitious materials over time. In addition, CBP and the Advanced Simulation Capability for Environmental Management (ASCEM), described in the Groundwater and Soil Remediation section of this report, will develop a software interface and conduct a joint demonstration using both CBP and ASCEM codes to predict performance and transport in a selected DOE facility. 


\section{Waste Processing Technical Exchange}

Since 2003, the Waste Processing Technical Exchange has been a forum for operations and engineering personnel and scientists to meet and exchange recent results of ongoing field operations and technology development to accelerate the transition of technologies from concept to field implementation.

- Sponsored by the DOE EM Office of Waste Processing and hosted by the Savannah River National Laboratory, the November 2010 Waste Processing Technical Exchange drew more than 275 participants to Atlanta, Georgia to discuss efforts to accelerate clean-up at the Savannah River, Hanford, and Idaho sites. In addition to those attending in person, about 100 others participated via inferactive live video feed. This year's technical exchange featured presentations and posters on a wide range of topics of immediate interest, including waste retrieval, waste form development, pretreatment, facility readiness and startup, performance assessment and operational improvements at the tank farms. I

The turnout for this eighth Waste Processing Technical Exchange was a record. Assistant Secretary for Environmental Management Dr. Inés Triay kicked off the proceedings. The attendees included DOE and contractor personnel from Savannah River, Hanford, and Idaho plus personnel from six national laboratories as well as representatives from nine universities and several government agencies.

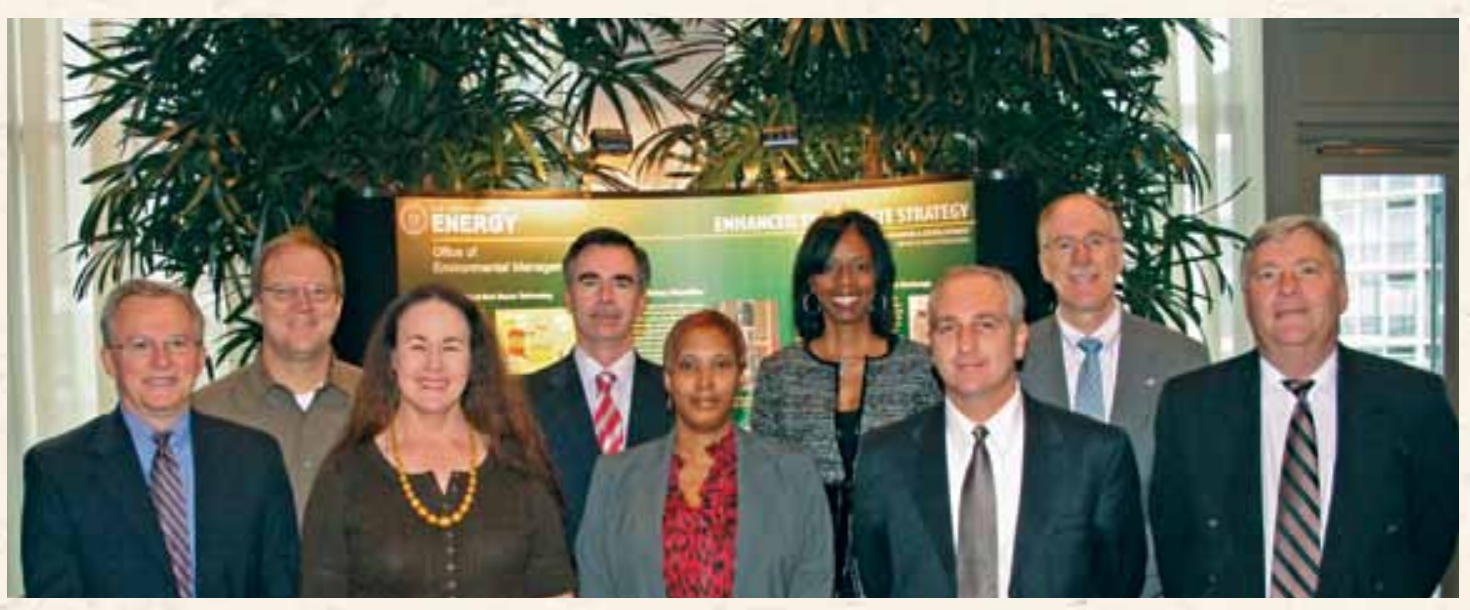

Office of Waste Processing Director Steve Schneider (second from right), SRNL Associate Laboratory Director for Environmental Management Dr. Jeff Griffin (fourth from left), and SRNL organizers of Waste Processing Technical Exchange 2010 


\section{GROUNDWATER \& SOIL REMEDIATION}

The Department of Energy (DOE) has responsibility for one of the largest and most complex groundwater and soil clean-up missions in the world, due to the sheer volume of contaminated groundwater and soil, range of geologic settings, and diversity of contaminant types. Within DOE sites, there are 10,000 areas needing groundwater and/or soil remediation.

During Cold War-era nuclear weapons production, the subsurface at DOE sites became contaminated with chemicals and radionuclides due to planned waste disposal operations and unplanned spills and leaks. Many of the contaminants, including chlorinated solvents, metals, and radionuclides, have migrated to the water table, creating large groundwater plumes. Both the contaminated soils and groundwater plumes now require clean-up. A great deal of work has been performed using traditional and innovative technologies, but significant work remains to be done. Improved technologies and approaches are needed to ensure that the clean-up is safely and expeditiously completed.

The Office of Groundwater and Soil Remediation within the EM Office of Technology Innovation and Development is responsible for providing site managers with advanced technologies and approaches for remediating contaminated subsurface areas at DOE sites. The goals are to reduce risks to the public and the environment, improve safety, and reduce remediation costs and schedules.

Some major fiscal year 2011 activities contributing to these efforts are

- Deep Vadose Zone Applied Field Research Initiative .

- Advanced Simulation Capability for Environmental Management

- Attenuation-Based Remedies for the Subsurface Applied Field Research Initiative

- Applied Field Research Initiative for the Remediation of Mercury and Industrial Contaminants

- SRNL/Chernobyl IRL Radiation Ecology Collaboration. 


\section{Deep Vadose Zone Applied Field Research Initiative}

Remediation of chemical, metal, and radionuclide contamination in the deep vadose zone, that is, the water-unsaturated sedi-, ment below the soil and above the groundwater, is a significant challenge in several regions of the United States, particularly in arid and semi-arid regions where the zone is the thickest. Through the Deep Vadose Zone Applied Field Research Initiative, DOE is leveraging investments and scientific expertise from the Department, national laboratories, commercial entities, and others to develop effective long-term solutions to one of the nation's most difficult clean-up challenges and to protect our water resources.

During 2011, an advanced geophysical inversion code was developed through an unprecedented collaboration of Pacific Northwest National Laboratory, hydroGEOPHYSICS, Inc., CH2M Hill Central Plateau Remediation Contractor, and Washington River Protection Solutions, with support in imaging the results from the Advanced Simulation Capability for Environmental Management. Development of the geophysical inversion code culminated in a field demonstration of its use at the $\mathrm{BC}$ cribs and trenches in the 200 Area at the Hanford site in southeastern Washington State.

This geophysical imaging technology will enable scientists to locate, view, characterize, and monitor subsurface contaminant plumes in situ; be more certain in estimating the three-dimensional distribution of parameters that govern groundwater flow and transport; monitor and validate remediation activities in real-time phases; and monitor post-remedial performance, including contaminant mobilization or demobilization.
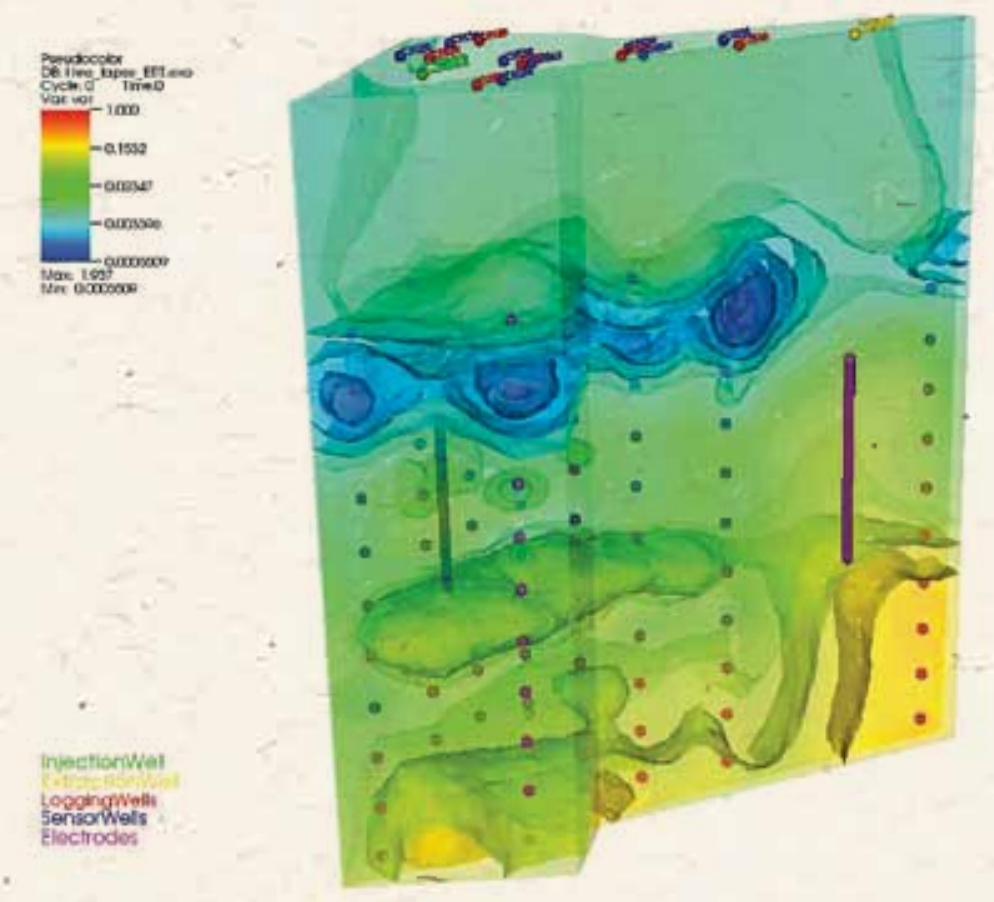

Three-dimensional visualization of vadose zone contamination for Hanford Site BC cribs and trenches using advanced high-resolution geophysical inversion code technology 


\section{Advanced Simulation Capability for Environmental Management}

The DOE EM Office of Technology Innovation and Development is supporting a multi-national-laboratory effort to develop the Advanced Simulation Capability for Environmental Management (ASCEM). ASCEM is an emerging state-of-the-art scientific approach and software tool for understanding and predicting contaminant fate and transport in natural and engineered systems. The modular and open-source high-performance computing tools will facilitate standardized assessments of performance and risk for EM clean-up and closure decisions.

In fiscal year 2011, the ASCEM team completed Phase I demonstrations of the initial tools, showing value to the EM community in High Performance Computing, Data Management, Visualization, and Uncertainty Quantification. The demonstrations in FY2011 emphasized individual capabilities. In fiscal year 2012, the Phase II demonstrations will emphasize integration of the different capabilities in the ASCEM Platform. ASCEM also will release an initial version of the code to selected users for the purpose of testing. A version of the code with appropriate quality assurance is expected in the fifth development cycle.

Also in 2011, the ASCEM team continued to engage end-users in ongoing interactions with the Performance Assessment Community of Practice and the Low-Level Waste Disposal Facility Federal Review Group and through direct interactions with practitioners. A User Steering Committee was formed to provide

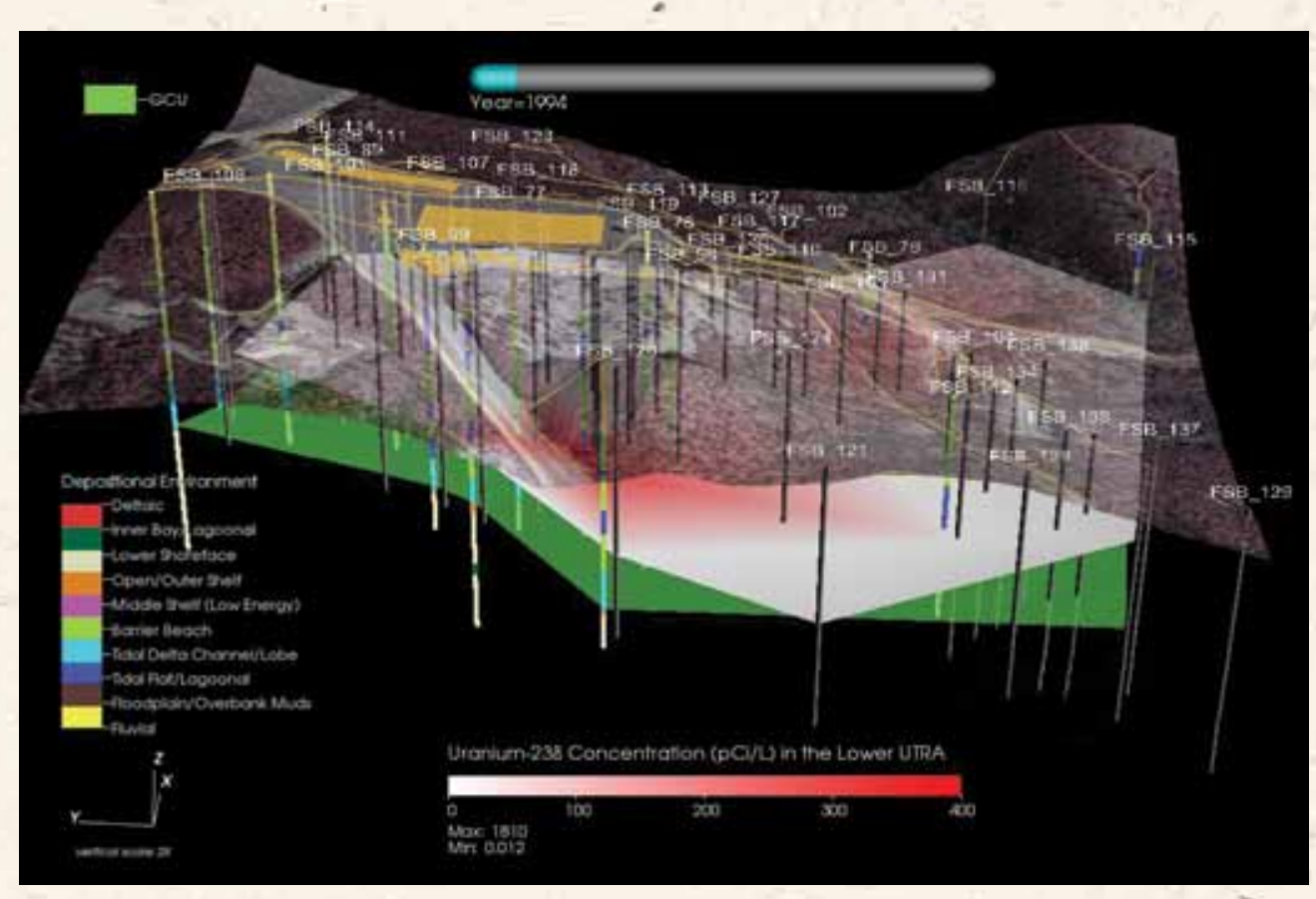

Single frame of a movie showing the evolution of a uranium plume at the Savannah River Site, F-Area. The image shows the surface of the site including seepage basins (mustard color), the stratigraphy of well bores (color coded per the legend), and uranium contamination (red).

higher level input from a programmatic and regulatory perspective. The first formal meeting was held in January 2011. The User

Steering Committee provided recommendations to the ASCEM management team. A key emphasis of the recommendations is to identify a path forward for integration of end-users in actual applications and demonstrations of the tools, which represents a shift from the initial 2010 focus on identification of requirements to identification of opportunities for direct engagement of the developing ASCEM tools in demonstrations at the DOE sites. Several observations and recommendations also were captured in the August 2011 external peer review of the ASCEM program, which concluded that the ASCEM program would be of great benefit to the EM Mission. 


\section{Applied Field Research Initiative for the Remediation of Mercury and Industrial Contaminants}

The Applied Field Research Initiative for the Remediation of Mercury and Industrial Contaminants was created to map mercury subsurface distribution and achieve mercury mass reduction in water at the Y-12 Nation Security Complex (NSC) in Oak Ridge, Tennessee. Strong partnerships and leveraging of resources will accelerate and improve the translation of knowledge from fundamental and applied science into demonstrated, field-deployable remediation technologies. The initiative is a collaborative effort of the DOE Office of Environmental Management, Oak Ridge Operations, the DOE Office of Science, national laboratories, and industrial, academic, and contractor partners.

During fiscal year 2011, research focused on improving conceptual understanding of mercury fate and transport, developing and demonstrating new methods for identifying mercury in the subsurface, and assessing treatments for waterborne mercury.

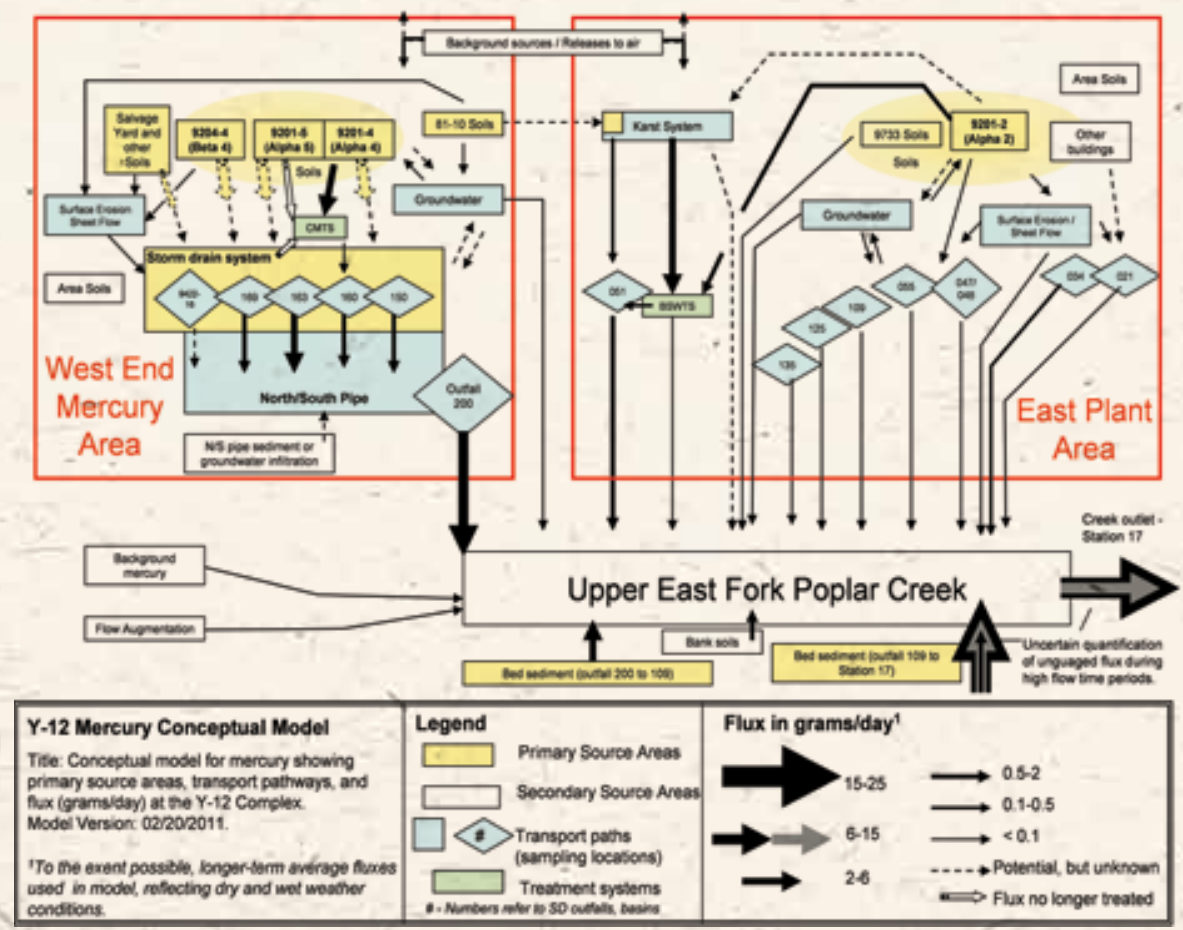

Conceptual model diagram for mercury at the Y-12 NSC (2011)
A new conceptual model of mercury behavior at the Y-12 NSC was completed in March 2011 by Oak Ridge National Laboratory (ORNL) and Savannah River National Laboratory (SRNL). The model identified mercury distribution and fluxes associated with known mercury use areas and outfalls, providing a valuable reference for developing surface water remediation and source zone removal strategies and highlighting areas requiring further study.

Characterization research was also conducted by ORNL and SRNL to facilitate rapid, cost-effective identification of subsur-, face mercury. For example, a membrane interface probe system, developed from commercial technology, was demonstrated to detect elemental mercury at depths of nearly thirty feet. Soil gas probes for detecting subsurface mercury were also assessed. Complementary laboratory-based work used chemical extractions and spectroscopic methods to determine mercury speciation in soil cores collected during field studies.

Water treatment studies have been centered on sorbentbased methods for mercury removal. Future work will analyze the predicted impacts of proposed remediation strategies on mercury fluxes, continue to elucidate the nature and extent of mercury contamination at the Y-12 NSC, and investigate soil treatment methods. 


\section{SRNL/Chernobyl IRL Radiation Ecology Collaboration}

Collaborative work between the United States Department of Energy's Savannah River National Laboratory (SRNL) and the Chernobyl Center's International Radioecology Laboratory (IRL) has led to a special issue of the Health Physics Journal entitled

"Radiation Monitoring and Radioecology Research in the Chernobyl Exclusion Zone - 25 Years After the Accident" (Vol. 101, No. 4).

- Under the auspices of the International Program within the DOE EM Office of Technology Innovation and Development, SRNL and the Ukraine's IRL have collaborated on various research projects in the Chernobyl Exclusion Zone, which remains heavily contaminated as a result of the 1986 accident at the Chernobyl Nuclear Power Plant. Unfit for residential or agricultural use, the Exclusion Zone is uniquely suited for studying radionuclide distribution, movement and effect.

"Even though Chernobyl is fundamentally different from any US nuclear site, there is much we can learn in the surrounding area," said Eduardo Farfan, co-principal SRNL investigator for interactions with IRL. "As a result of the accident, the nearby area has become a unique laboratory where we can observe how the environment changes and how animals and plants change over time following contamination." "We share a lot of the same interests with our colleagues at IRL," said Farfan. "They are developing techniques and technologies for cleaning up the environment in the region that might ultimately be useful to DOE."

Papers published in Health Physics in 2010 covering the first few studies led to interest in the special issue, which is sponsored by DOE-EM's International Program and SRNL. The current papers describe research including:

- environmental radiation monitoring of the Chernobyl Exclusion Zone - history and results 25 years later

- a study of the environmental problems associated with decommissioning the Chernobyl Nuclear Power Plant Cooling Pond

- a study of the properties of certain microscopic fungi found in the Chernobyl Exclusion Zone that appear to protect them from the effects of radiation

- a new technique for measuring the radioactive content of live animals in their natural habitat

- a study of Scots pine trees in the Exclusion Zone as a way of understanding the effects of chronic internal and external radiation exposure on vegetation

- a summary of radioactive waste management.

Under a new agreement signed in 2010, SRNL and IRL continue to collaborate on radiation ecology research, looking for mutually beneficial projects in a variety of subjects related to radiation ecology. In one project funded by the International Program, an SRNL expert in nature-based environmental cleanup techniques, Dr. Miles Denham, is working with IRL to study the potential of engineered soil amendments to enhance natural decontamination processes for cleaning up the area. This project also offers benefits to DOE, as the contaminated soils of the Chernobyl Exclusion Zone provide an excellent analogue to many of DOE's soil contamination problems.

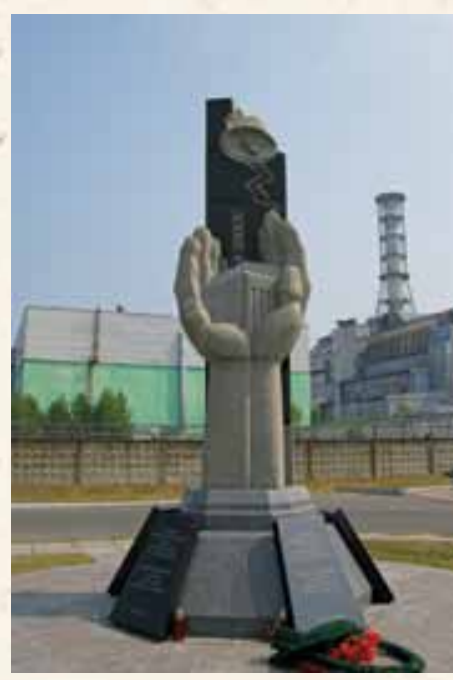

Monument in Memory of Chernobyl Disaster, Kiev Region, Ukraine 


\section{NUCLEAR MATERIALS DISPOSITION}

The Office of Nuclear Materials Disposition (NMD) within the DOE EM Office of Technology Innovation and Development is responsible for managing and disposing of spent nuclear fuel and surplus nuclear material, including plutonium. As part of this mission, NMD identifies and prioritizes technology development and collaborates with internal and external parties to leverage resources.

In fiscal year 2011, NMD identified technology development activities to support extended storage and drafted an accompanying Overview of DOE Storage Capabilities.

Also in fiscal year 2011, NMD initiated research and development activities to assure the continued safe and secure management of $\sim 13$ metric tons of plutonium and the continued safe storage of $>2,400$ metric tons of spent nuclear fuel until disposition paths are determined. In addition to utilizing expertise from the National Spent Nuclear Fuel Program and national laboratories and incorporating advice from external oversight entities, NMD sought to build on the experience of international partners. Those collaborations include:

- US DOE/UK NDA Collaborative Nuclear Materials Management Task Plans

- US DOE/UK NDA Workshop on Plutonium Management

- DOE SRNL/UK University of Manchester Partnership to Evaluate Stress Corrosion Cracking of Plutonium Storage Containers

- US DOE/ Atomic Energy of Canada Ltd. Spent Nuclear Fuel Collaboration

- US DOE/ PURAM of Hungary Information Exchange on Spent Nuclear Fuel Dry Storage 


\section{US DOE/UK NDA Collaborative Nuclear Materials Management Task Plans}

In 2011, the United States Department of Energy (US DOE) and the United Kingdom's Nuclear Decommissioning Authority (UK NDA) drafted a set of task plans describing potential collaborative research and development efforts in nuclear materials management and disposition that could benefit both governments. The objective is to expedite development of more safe, secure, cost-effective, and innovative methods for storage and disposition of nuclear materials by leveraging past experience and technology development activities performed and planned in both the US and UK.

The DOE and NDA will seek to optimize results in nuclear materials management through exchange of technical information, plans for near-term projects, and strategies for long-term projects.

The tasks plans identify these potential areas of collaboration regarding spent nuclear fuel handling, treatment, and storage:

1. Fuel drying and storage

2. Aging management

3. Non-standard fuels.

Regarding plutonium management, the task plans identify these potential areas of collaboration:

1. Continued safe storage of excess plutonium materials

2. Processing and stabilization of plutonium-bearing materials

3. Characterization of excess plutonium materials for potential use as feed into the Mixed Oxide Fuel Fabrication Facility

4. Evaluation of disposition options for excess plutonium.

The teams have shared information remotely and in a bilateral workshop on plutonium management sponsored by NMD. The DOE and NDA are pursuing funding to undertake more substantive collaborative activities. 


\section{US DOE/UK NDA Workshop on Plutonium Management}

On April 19-21, 2011, NMD sponsored a bilateral workshop on plutonium materials management for the DOE Office of Environmental Management (EM) and the UK NDA, which consolidates the civil nuclear assets of the UK. The workshop was hosted by the Savannah River National Laboratory at the Savannah River Site in South Carolina. Participants included staff from DOE-EM Headquarters, DOE-Savannah River, DOE-National Nuclear Security Administration, UK NDA, UK National Nuclear Laboratory, Sellafield Sites Ltd, Los Alamos National Laboratory, Shaw-Areva MOX, and Savannah River Nuclear Solutions. The purpose of the workshop was to review

1. technical activities in plutonium management, including stabilization, packaging, and long-term performance of storage containers,

2. surveillance activities, including destructive and non-destructive examination, and

3. strategies for the disposition of the surplus plutonium, such as using immobilization and converting plutonium into mixed oxide fuel.

The two-and-a-half-day workshop also included tours of the Defense Waste Processing Facility and the Mixed Oxide Fuel Fabrication Facility, which is under construction at SRS.

The EM and NDA benefited from exchanging their experience and expertise in the management and disposition of plutonium materials. The discussions enabled assessment and understanding of the overall plutonium program strategies in the US and UK and highlighted the key differences in the programs. The workshop also identified potential areas for collaborative research and technology development activities between the EM and NDA, which were subsequently incorporated into the DOE/NDA collaborative task plans.

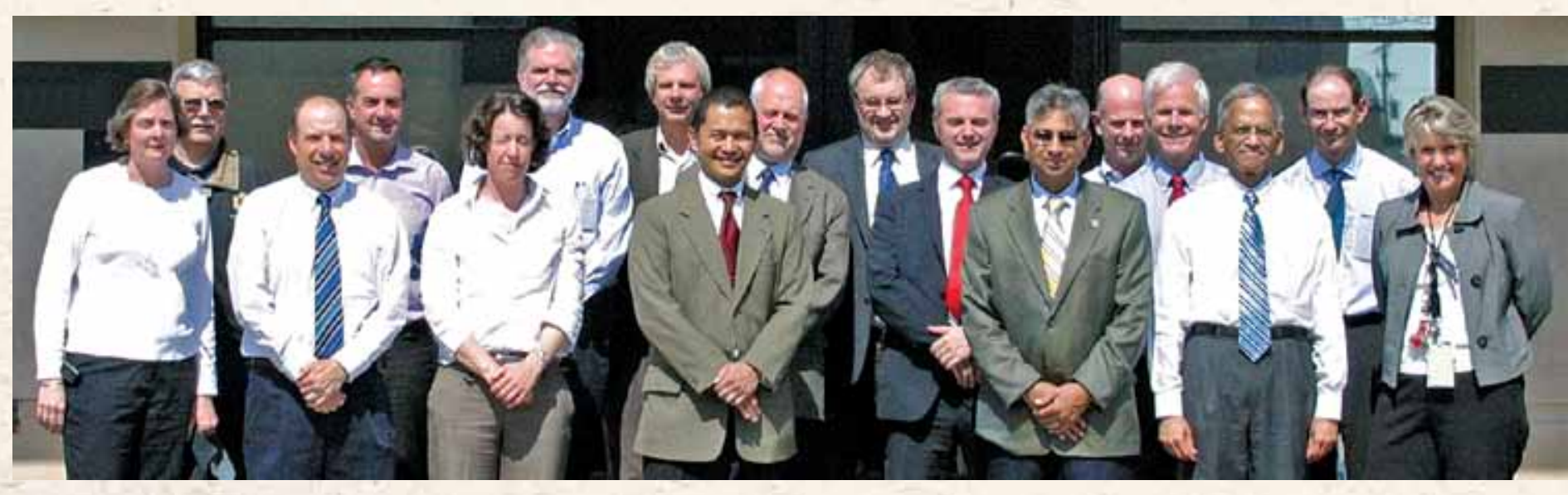




\section{DOE SRNL/UK Univ. of Manchester Partnership to Evaluate Stress Corrosion Cracking of Plutonium Storage Containers}

To build upon initial laboratory and field surveillance studies performed by the Savannah River National Laboratory (SRNL) and Los Alamos National Laboratory (LANL), SRNL has recently initiated collaborative research and development activities with the University of Manchester, a public research university in Manchester, United Kingdom, to understand stress corrosion cracking (SCC) of 300 Series stainless steel, which is used as the material of construction of plutonium storage containers.

SRNL and LANL developed an integrated corrosion program to improve the limited understanding of corrosive gas behavior within plutonium storage containers and the potential for stress corrosion cracking. Initial laboratory and field surveillance studies have documented the occurrence of pitting and general corrosion on the stainless steel plutonium containers. Stress corrosion cracking is an electrochemical process triggered by the presence of an electrolyte, along with moisture, on the container material. The tendency for corrosion is related to the composition and amount of electrolytes, such as alkaline earth salts, in combination with a level of relative humidity that can cause deliquescence of those salts. The tendency for moisture adsorption depends on the relative humidity of the environment inside the container, and the relative humidity depends on the moisture content of the container, the amount and type of salts present in the container, and the temperature or temperature gradients within the container.

The partnership between SRNL and the University of Manchester will focus analytical and experimental effort on the role of humidity on SCC as it pertains to head space corrosion and as it is influenced by or influences the role of salts in the containers to develop a fundamental understanding of SCC in plutonium containers.

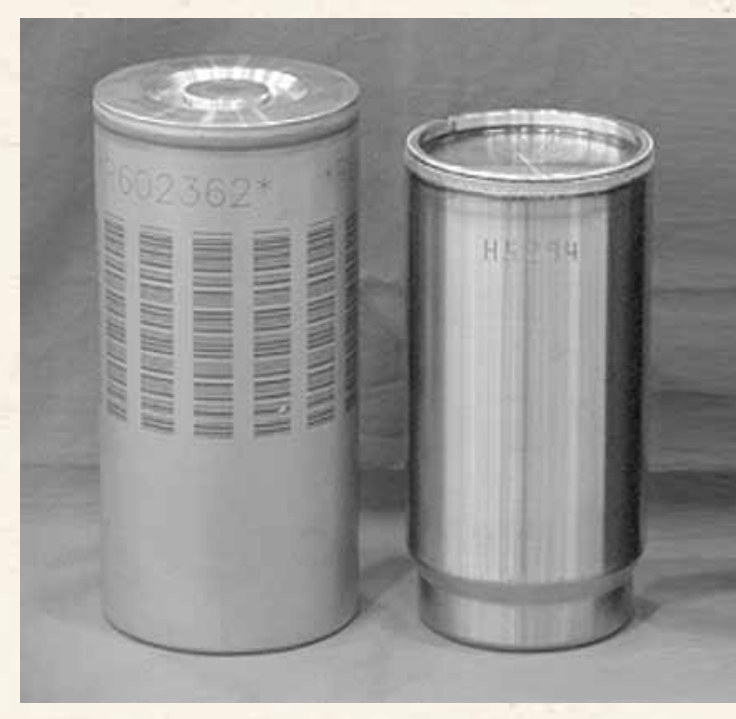

DOE standard stainless steel plutonium storage container 


\section{US DOE/ Atomic Energy of Canada Ltd. Spent Nuclear Fuel Collaboration}

On June 14-16, 2011, representatives from the DOE EM Office of Technology Innovation and Development met in Canada with representatives of the Nuclear Legacy Liability Program of Atomic Energy of Canada Limited (AECL) to discuss potential areas of collaboration, one of which was spent nuclear fuel (SNF) disposition. During the visit, the EM delegation toured several facilities at the AECL Chalk River Laboratory. (CRL) site. The CRL waste inventories are similar to those of US facilities but in much smaller volumes. The AECL Tile Hole Investigation and Retrieval Project at CRL is going to transfer spent research reactor fuel currently stored underground in vertical cylindrical concrete structures called "tile holes" to the new above-ground dry-storage Fuel Packaging and Storage (FPS) Facility. EM has placed its Idaho National Laboratory (INL) SNF in dry storage and plans to retrieve and package the fuel into a "road ready" condition to meet the Idaho Settlement Agreement dates of having all SNF in dry storage by 2023 and out of Idaho by 2035. The Canadian project will be completed prior to the similar activities at the Idaho site. EM hopes to benefit from lessons learned in AECL's use of advanced remote handling equipment to inspect, characterize and handle spent fuel to minimize personnel risk. Reciprocally, AECL is interested in information exchange related to underwater assay, characterization, and maintenance technologies and systems used by EM.

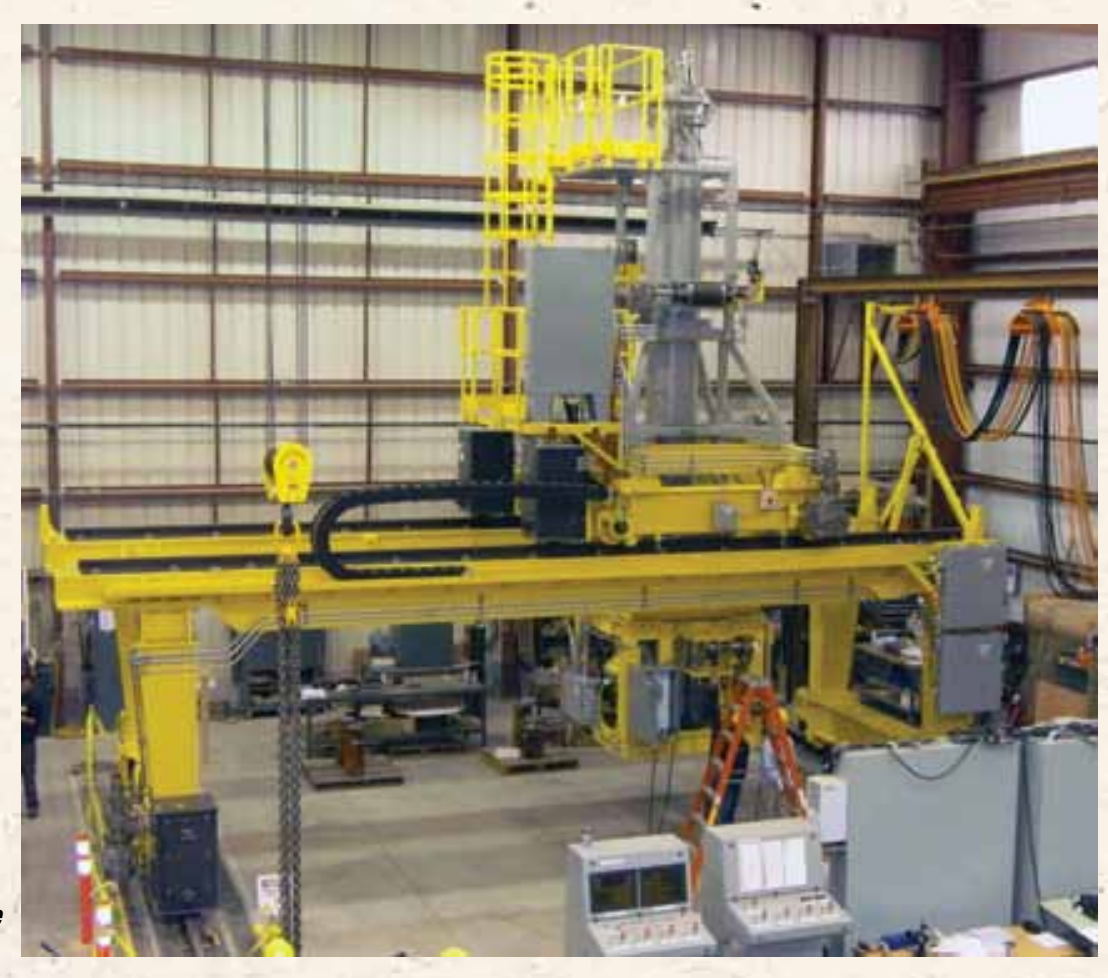




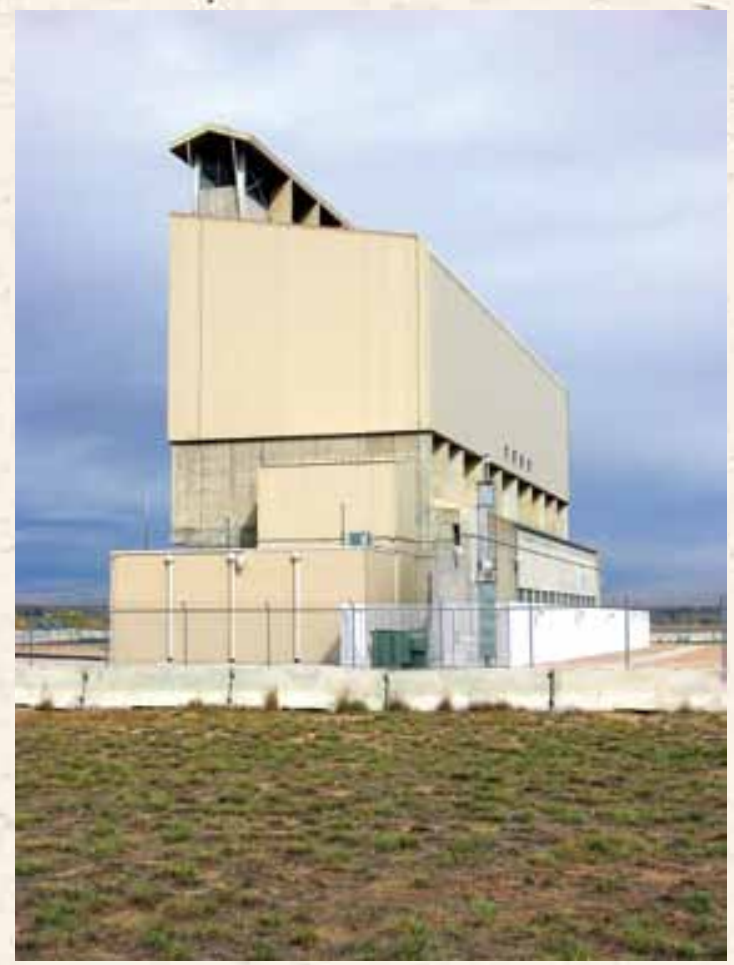

\section{US DOE/ PURAM of Hungary Information Exchange on Spent Nuclear Fuel Dry Storage}

The US DOE and the Public Agency for Radioactive Waste Management (PURAM), the Hungarian national agency responsible for radioactive waste handling and disposal, established an informa-

tion exchange program in the 2009 Memorandum of Understanding (MOU) Relating to Operation of Modular Vault Systems for Storage of Spent Nuclear Fuel. One American facility and one Hungarian facility-the Independent Spent Fuel Storage Installation (ISFSI) Modular Vault Dry Store (MVDS) near the former Fort St. Vrain Nuclear Generation Station in Platteville, Colorado, and the MVDS in the town of Paks, Hungary, the location of the only Hungarian nuclear power plant- are two of the few MVDS facilities of similar design worldwide. To facilitate the exchange of information and lessons learned relating to the operation of spent fuel vault storage systems, each participant prepares an annual report for submission to the other. The Director of the DOE Office of Technology Innovation and Development submitted the 2011 FSV ISFSI Operational Experience Annual Report to PURAM in September. The report addresses FSV ISFSI operations, technical aspects, design aspects, equipment maintenance, regulatory compliance, and other areas of mutual interest.

Fort St. Vrain Modular Vault Dry Store 


\section{DEACTIVATION \& DECOMMISSIONING}

The Department of Energy (DOE) is the custodian of approximately 3,000 facilities that were constructed and used over the past 65 years to develop nuclear materials for scientific, domestic, and defense purposes. Most of these facilities were designed for specialized purposes, and over time the equipment and facilities have become obsolete. Many of the facilities are large and complex, with unique design features, e.g., six-foot thick walls. Since the early days of the Manhattan Project in the 1940s through the 40 years of the Cold War, the Department was under schedule-driven deadlines to deliver products. Old facilities were often abandoned, as additional facilities were built for newer missions and changes in technology. When the Cold War ended, a huge environmental legacy was revealed, including a large inventory of radiological facilities needing final disposition.

The process of taking an active/excess/abandoned facility to a final disposition end state is called deactivation and decommissioning (D\&D). Because of residual radioactivity and other hazardous constituents and the physical condition of EM's facilities, D\&D presents unique hazards that must be addressed from a safety, programmatic, environmental, and technological standpoint.

The Office of Deactivation and Decommissioning within the DOE Office of Environmental Management focuses on innovative applications and timely insertion of existing commercially available technologies, processes and hardware to identify and address D\&D risks and challenges. The program supports the development of informed facility D\&D strategies; enhanced verifiability of the efficacy of $D \& D$ operations; increased productivity and personnel safety of $D \& D$ operations; facilitation of acceptable facility end-states, and independent verification.

Priority projects in fiscal year 2011 that are expected to produce demonstrable D\&D benefits in the near future include:

- Remote Sensors to Monitor In Situ Decommissioned Structures

- RadBall Adaptation for EM D\&D

- Remote Inspection of Contaminated and Deteriorated Stacks

- Innovations for Sodium-Cooled Reactor D\&D

- Polymeric Hydrogels for Radiation Decontamination. 


\section{Remote Inspection of Contaminated and Deteriorated Stacks}

Oak Ridge National Laboratory (ORNL) and Florida International University (FIU) are developing a stack characterization system (SCS) for remote inspection of highly contaminated and structurally deteriorated stacks and stack-like structures. The SCS is a crane-deployed remote inspection and sampling tool designed to be inserted into the top of the stack and to progress down through the stack from the top. The core mission is video inspection, radiation monitoring, smear sampling, and core drilling of the subject stack to determine structural integrity and extent of contamination. Sample collection is managed through two instrument bays that are pressed against the inner stack walls. The remote automated smear sampling system is capable of collecting up to 20 samples in a single campaign. The remote core drill is capable of collecting up to six samples in one campaign. To minimize burdensome cabling systems, the SCS is battery powered and communicates to the operator station via wireless link. The battery pack is sized and the powered equipment designed such that the SCS will run for an entire day. It can be completely recharged overnight.

1

During fiscal year 2011, the SCS mechanical and control systems were assembled and preliminary checkout was completed. ORNL Technology Transfer initiated contact with multiple commercial companies interested in acquiring the technology for use both within the Department of Energy community and for industrial use wherever large stacks are used.

ORNL Technology Transfer has defined a cold test demo that will maximize the impact and value for potential end users. SCS performance will be demonstrated in the relatively clean and structurally sound ORNL Stack 7614 in Fall 2011. ORNL has also expressed interest in the technology for use in the inspection of its highly contaminated, structurally compromised Stack 3039 in fiscal year 2012, which would be the system's first radiological deployment.

Several useful subsets of the technology have already been identified. A cranedeployable stand-alone camera package developed for testing radio and video performance of the SCS components may be valuable for early rapid deployment for stack inspection. The automated smear sampler and the semi-automated core drill sampler have broad potential use across the DOE community for any remote sampling needs.

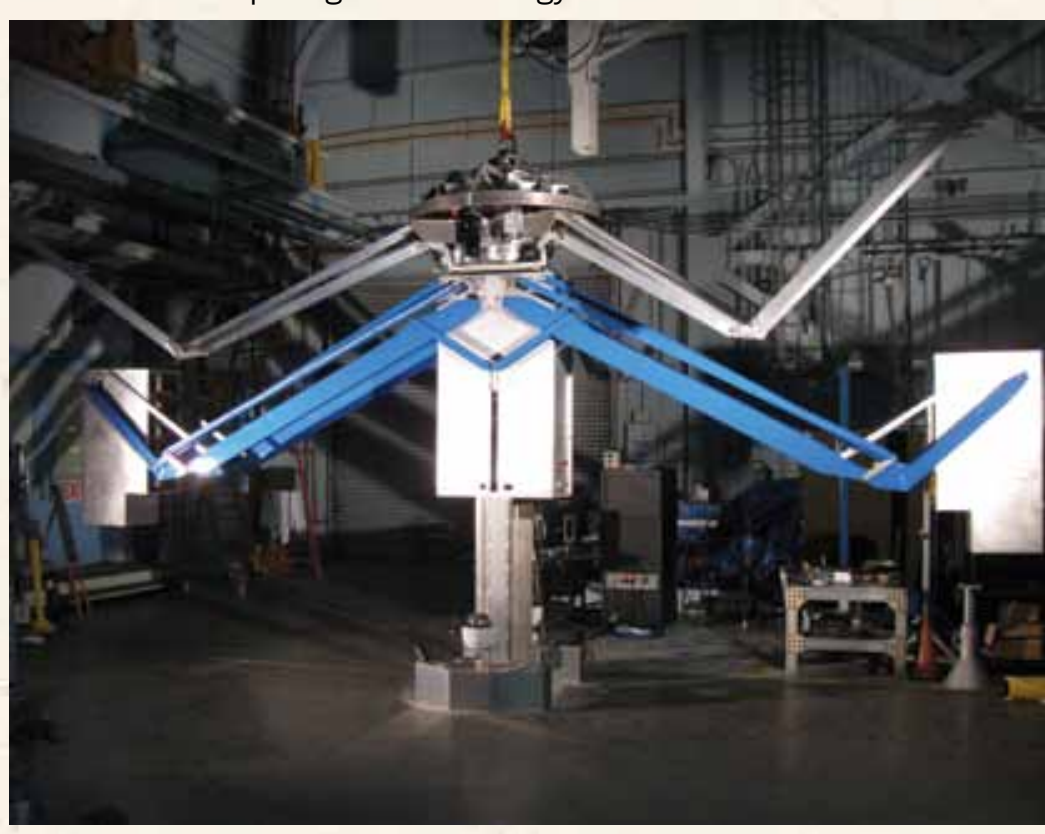

Stack Characterization System 


\section{Innovations for Sodium-Cooled Reactor D\&D}

During fiscal year 2011, the Idaho Cleanup Project of CH2M-WG Idaho, LLC (CWI) advanced an optimized baseline approach to remove sodium remaining after initial cleaning of the pipes and tank of the sodium-cooled Experimental Breeder Reactor II (EBR-II) at Idaho National Laboratory to allow D\&D of the reactor. Preparation for sodium passivation moved into field-scale mock-up testing involving aqueous treatment of residual sodium in the "yard piping" system, the piping system connecting the reactor's interme- . diate heat exchanger to the secondary system located in an adjacent building. In February, CWI successfully demonstrated the field-scale treatment of residual sodium by injecting and circulating a citric acid solution through 200 feet of 12 inch diameter piping. Citric acid was selected as the preferred reagent to neutralize sodium hydroxide resulting from sodium-water reaction, yielding a sodium-citrate product, thus forming a buffered system. Reaction of sodium with the citric acid solution generates hydrogen, which is monitored with off-gas instrumentation. Based on the success of this field-scale test, CWI is currently finalizing installation for full-scale treatment of residual sodium in the EBR II reactor vessel. This task is expected to be completed by December 2011.

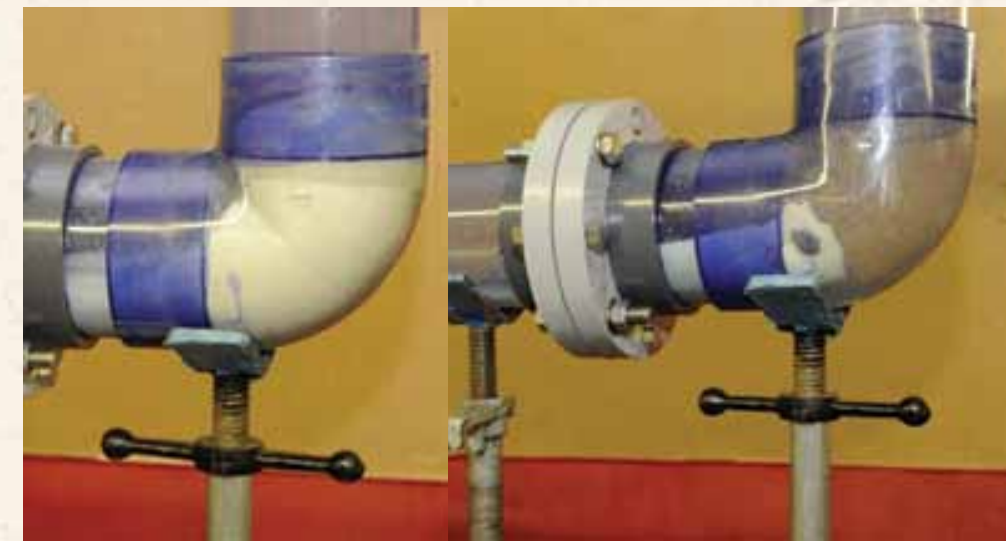

Photo of sodium hold-up in field-scale mock-up testing before and after treatment with citric acid

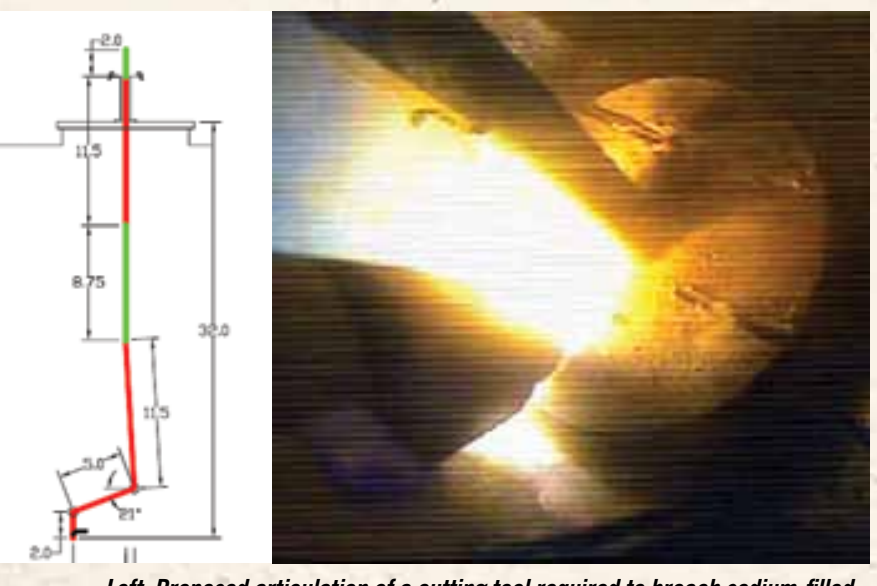

Left: Proposed articulation of a cutting tool required to breach sodium-filled components. Right: Successful cutting of a pressure transducer in the EBR-II reactor vessel using a remotely deployed plasma cutting torch.

Also during fiscal year 2011, an articulated boom and specialized cutting tools were successfully developed and deployed to size-reduce sodium-filled components of the (EBR-II).

The sodium-filled components are inaccessible with normal cutting tools and methods. For example, most of the targeted components consist of $1 / 2$-inch pipe and 'pressure transducers located 32 feet below the grade only accessible through a limited number of 8 -inch diameter ports on the top head of the reactor vessel. Further complicating the size-reduction project was the high radiation field associated with the activated components near the core region of the reactor.

In order to facilitate size-reduction of the components while keeping worker exposure as low as reasonably achievable, the DOE EM Office of Deactivation and Decontamination supported development of a long-reach boom capable of positioning and manipulating various cut-

ting tools, including a plasma cutting torch and electric and pneumatically-driven grinders, inside the reactor vessel. Not only can the tool boom reach 32 feet below grade, but once it is deployed, an operator can position the tool within $1 / 4$-inch accuracy to a component located within a 5 -foot sweep radius. 


\section{Polymeric Hydrogels for Radiation Decontamination}

DeconGel ${ }^{\circledR}$ decontaminant is used for remediation of radiological, nuclear, and hazardous chemical substances at DOE sites. The DOE EM Office of Deactivation and Decommissioning has collaborated with CBI Polymers, Inc. in the optimization of DeconGel, which is a decontamination gel that is spread or sprayed on contaminated surfaces, allowed to dry, and then peeled away, taking with it the encapsulated contaminants.

Pilot batch production of second generation prototype formulations (DeconGel 1108 brushable and DeconGel 1128 sprayable) contain an additive that provides improved efficacy against cesium, transuranic waste, and hydrophobic contaminants. The new formulations--which are non-flammable, have improved film toughness and peelability, and have reduced foaming (compared to the original DeconGel 1101 and DeconGel 1121)--were successfully completed in August 2011. These formulations were tested at the Idaho National Laboratory under the direction of the Environmental Protection Agency's (EPA) National Homeland Security Research Center through the Technology Testing and Evaluation Program (TTEP). The tests showed improved decontamination efficacy against cesium on porous concrete $(67 \%$ removal after 2 applications) as compared to DeconGel 1101 (45\% removal after 2 applications) and to the primary peelable decontamination technology competitor (34\% removal after 3 applications; tested by the same method under EPA TTEP).

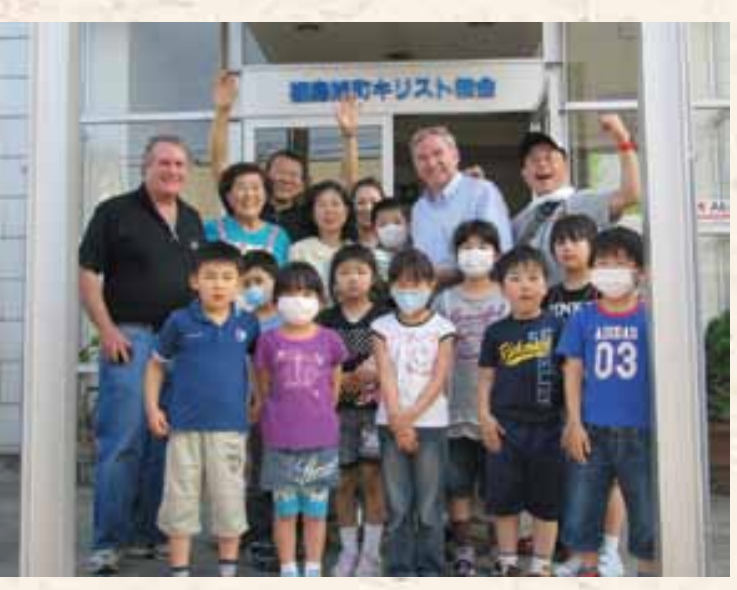

An elementary school in Fukushima City, Fukushima, Japan had residual fixed contamination of up to 25,000 CPM of Cs-134, Cs-137, and Co-60 on concrete, painted concrete, steel, painted steel, unpainted wood, wood and tile surfaces. DeconGel ${ }^{\circledR}$ was used and resulted in decontamination factors from $99 \%$ to $55 \%$.
The efficacy of the DeconGel decontaminant was also recently demonstrated in northern Japan in the wake of the Fukushima Daiichi Nuclear Power Plant crisis after the tsunami and earthquake struck Japan on March 11. A CBI Polymers team donated $\$ 250,000$ of DeconGel and technical services and was involved in training various agencies includ-

ing Tokyo Electric,Power Company, the Japan Self Defense Force, Tokyo Fire Department, Japan Medical Society, and the US Marine Corps, on the use of DeconGel. Members of CBI Polymer's team also donated product and technical expertise to Asahimachi Baptist School and Little Lamb Kindergarten, resulting in the successful decontamination of radioactive contamination from the schools' playground and outdoor surface areas, which had been closed because of the fear of radiation since the Fukushima Daiichi Nuclear Power Plant release.

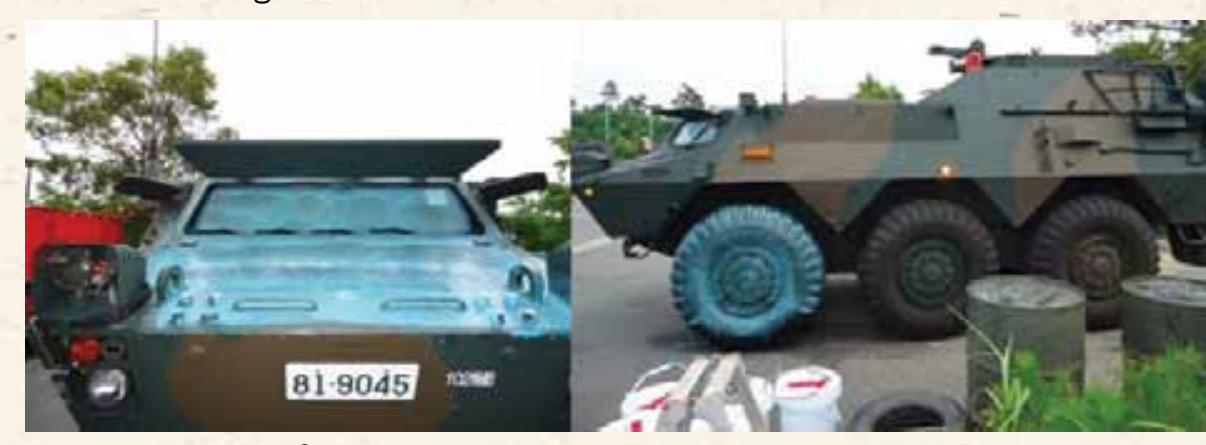

Demonstration of DeconGelø for the Japan Self Defense on a chemical troop carrier with residual fixed contamination of up to 15,000 CPM of Cs-134, Cs-137, and Co-60. DeconGel was used on metal, painted metal, rubber and glass surfaces with decontamination factors from $98 \%$ to $60 \%$. 


\section{INTERNATIONAL PROGRAM}

Facilitating engagement with multilateral international organizations as well as governmental, academic, and private sector institutions in individual nations, the International Program within the DOE EM Office of Technology Innovation and Development expands the technical depth of the EM program to expedite environmental clean-up and waste management efforts in the United States and in the rest of our world.

DOE EM's international engagement includes participation in international conferences and other forums, discovery and adaptation of promising technologies developed in other countries, and initiation of multi-national collaborations to address identified international needs as well as one-on-one collaboration with organizations in other countries on development of particular technologies.

The figure below shows some of the countries with which the EM International Program is already engaged in collaborative relationships or in which the International Program has identified collaborative opportunities to help address EM's technical needs.

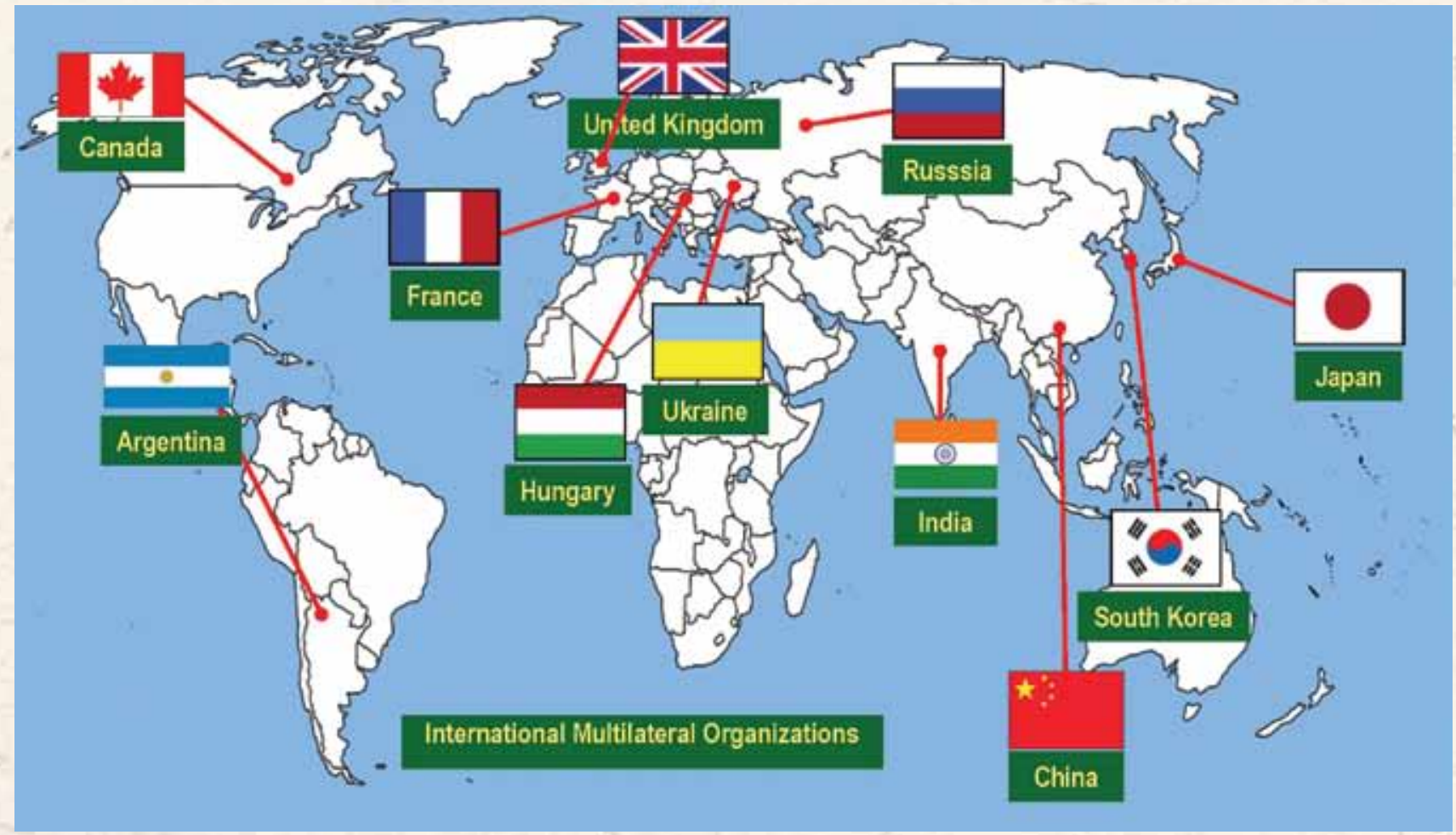




\section{Identification of Leveraging Opportunities}

EM actively participates in international conferences and other forums regarding global environmental management matters to learn the experiences of other nations; share United States experience; become acquainted with researchers, operations personnel, and policy makers from around the world; and identify opportunities for leveraging activities of organizations in other countries that are complementary to activities within EM.

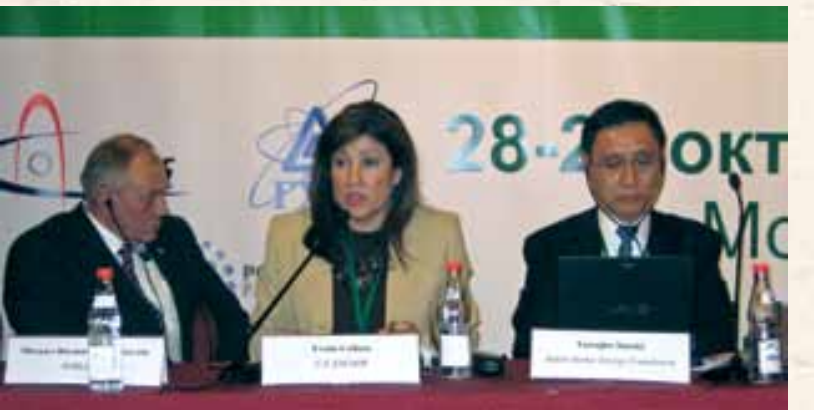

Yvette Collazo, Director, US DOE Office of Technology Innovation and Development, participates in a panel discussion with representatives of nuclear organizations from several countries at AtomEco—-2010 in Moscow, Russia.

During fiscal year 2011, for example, a delegation of officials from the DOE EM Office of Technology Innovation and Development traveled to Moscow, Russia, for the IV International Conference and Exhibition "AtomEco - 2010" on October 28-29, 2010. AtomEco focuses on radioactive waste management, spent nuclear fuel management, facility deactivation and decommissioning, and environmental remediation. In addition to presenting papers and otherwise participating in AtomEco sessions, the DOE delegation met with ROSATOM, the State Atomic Energy Corporation that incorporates more than 250 enterprises and scientific institutions of Russia, including all civil nuclear companies, nuclear weapons complex facilities, research organizations, and the nuclear-propelled fleet. The discussion concerned potential collaborative activities in all areas of importance to EM. Specific discussions focused on leveraging Russian expertise in the fundamental study of contaminant transport processes for modeling and simulation. DOE EM and ROSATOM continued the dialogue at the Waste Management Symposium in Phoenix in March 2011 and, in cooperation with the DOE Office of Nuclear Energy, in the District of Columbia in August 2011.

Also during fiscal year 2011, EM initiated collaboration with Atomic Energy of Canada Limited (AECL). In June 2011, a delegation from the DOE EM Office of Technology Innovation and Development traveled to Ontario, Canada, to meet with representatives of the AECL's Nuclear Legacy Liability Program to discuss technology development and nuclear waste management efforts. A number of potential areas for collaboration in waste processing, groundwater and soil remediation, deactivation and decommissioning, and nuclear materials management were identified, and a path forward was developed to facilitate future collaborative efforts. During the visit, the EM delegation toured several facilities at the AECL Chalk River Laboratory (CRL) site, which provided an opportunity to identify future collaboration between DOE and AECL in deploying environmental remediation technologies on actual nuclear waste. CRL has the potential of providing a radiological pilot-scale demonstration site for EM needs, which could potentially result in key data for risk reduction in deploying full-scale technologies in the US. The EM delegation also met in Ottawa, Ontario, with representatives of Natural Resources Canada (NRCan), which is responsible for the funding and oversight of Canada's environmental remediation efforts.

In September 2011, DOE EM Office of Technology Innovation and Development Director Yvette Collazo delivered the Chair's message to the 14th International Conference on Environmental Remediation and Radioactive Waste Management in Reims, France, charging participants from about 35 countries to "provide the scientific underpinnings for making changes...to educate and to advise policy makers at all levels of science and technology matters affecting the public interest...to preserve this planet and make it a better place to live, starting with the environment." Additional participants representing DOE EM organized and chaired technical sessions, took part in panel discussions, and presented technical papers. 


\section{Cross-Cutting Programmatic Benefits}

The International Program assists DOE EM in identifying ways to accelerate tank waste processing; groundwater and soil remediation; nuclear materials management; and facility deactivation and decommissioning.

DOE initiates multi-national collaborations to address identified international needs. For example, in 2009, DOE initiated a research program involving DOE EM and DOE NE and nuclear organizations in Europe and Asia to expand understanding of the behavior of the high-level waste glass form over geologic time scales in a variety of disposal environments. Fiscal year 2011 activities of this international research program are described in the Tank Waste Processing section of this report.

Under the auspices of the International Program, the US DOE's Savannah River National Laboratory and the Chernobyl Center's International Radioecology Laboratory in the Ukraine have collaborated on various radiation ecology research projects in the Chernobyl Exclusion Zone. Some recent collaborative projects are discussed in the Groundwater and Soil Remediation section of this report.

The DOE EM Office of Nuclear Materials Disposition is energetically seeking to build on the experience of international partners. Several fiscal year 2011 NMD collaborations regarding plutonium and spent nuclear fuel management with organizations in the United Kingdom, Canada, and Hungary are described in the Nuclear Materials Disposition section of this report.

Discovery of promising technologies developed by organizations in other countries may lead to adaptation of those technologies to EM purposes. Fiscal year 2011 activities to adapt one such technology, the RadBall ${ }^{\circledR}$ invented by the National Nuclear Laboratory in the United Kingdom, for EM application are described in the Deactivation and Decommissioning section of this report.

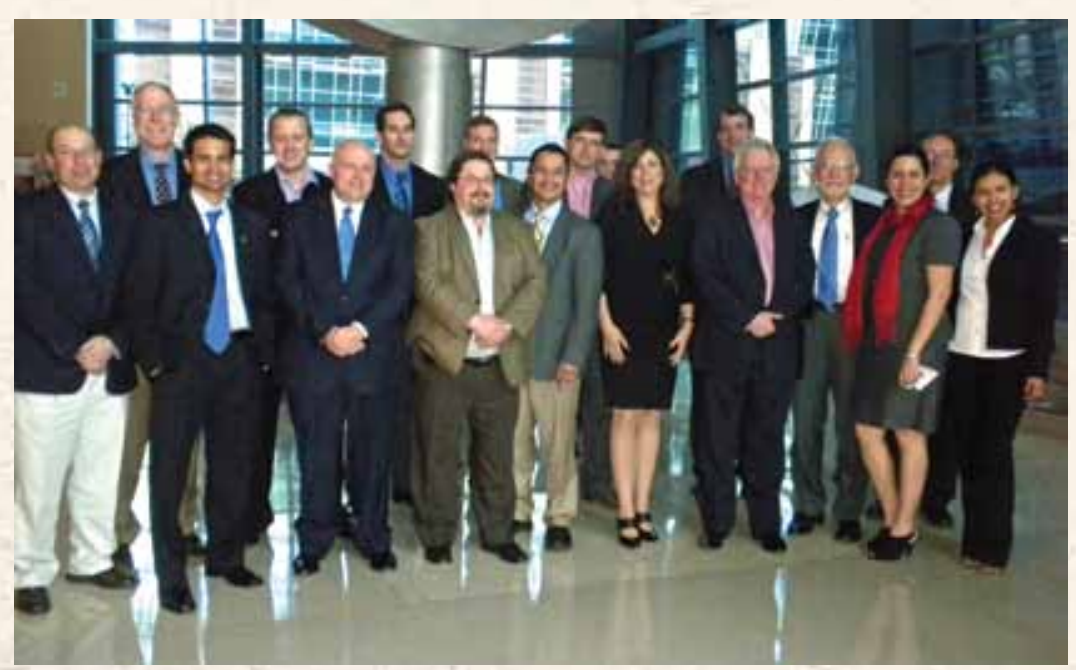




\section{CONCLUSION}

Through leadership in integration, collaboration, and communication, the Technology Innovation and Development program within the Department of Energy's Office of Environmental Management has transformed science and innovation into practical solutions to accelerate environmental clean-up and reduce costs during fiscal year 2011.

However, complex challenges remain, and significant advances in science and engineering are required to address both shortand long-term challenges to achieve mission objectives. Working at the intersection of basic science and needs-driven applied science and technology, the Technology Innovation and Development program is focused on addressing the greatest challenges facing the Department.

Until the EM clean-up mission is accomplished, the Office of Technology Innovation and Development will continue to marshal interdisciplinary research teams, collaborate with public and private partners, leverage research funding to maximize results, and advance environmental solutions to significantly reduce life-cycle cost, schedule, and risk. 
Editor Sheryl Ross Bush Designer Brent Douglas

EM Technical Integration Office

Savannah River National Laboratory

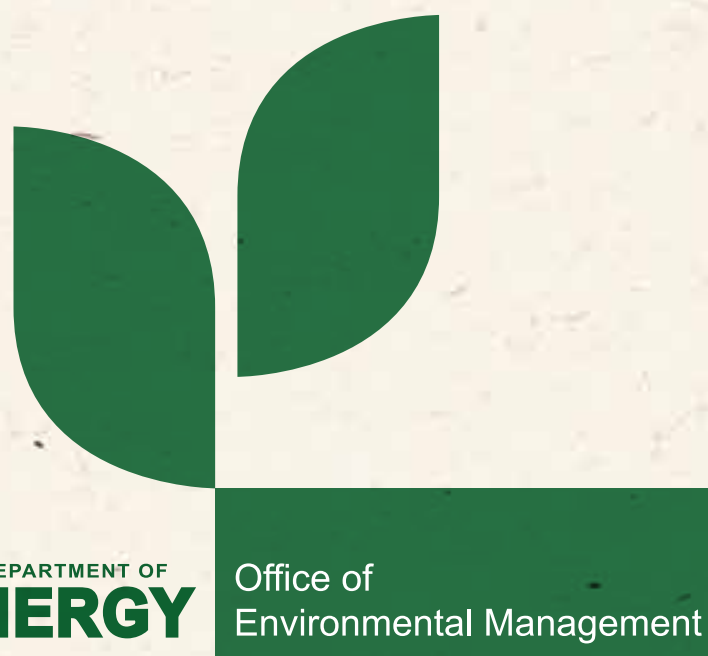


Yvette Collazo :

U.S. Department of Energy :

Attn: Office of Environmental Management : 1000 Independence Avenue SW

Washington, DC 20585:
Office of

Environmental Management 